\title{
Optimizing supply chain configuration with low carbon emission
}

Duxian Nie, Haitao Li, Ting Qu, Yang Liu and Congdong Li

The self-archived postprint version of this journal article is available at Linköping University Institutional Repository (DiVA):

http://urn.kb.se/resolve?urn=urn:nbn:se:liu:diva-170154

N.B.: When citing this work, cite the original publication.

Nie, D., Li, H., Qu, T., Liu, Y., Li, C., (2020), Optimizing supply chain configuration with low carbon emission, Journal of Cleaner Production, 271, 122539. https://doi.org/10.1016/j.jclepro.2020.122539

Original publication available at:

https://doi.org/10.1016/j.jclepro.2020.122539

Copyright: Elsevier

http://www.elsevier.com/

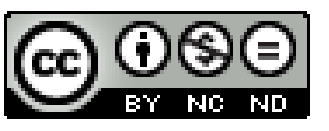




\section{Journal Pre-proof}

Optimizing Supply Chain Configuration with Low Carbon Emission

Duxian Nie, Haitao Li, Ting Qu, Yang Liu, Congdong Li

PII: S0959-6526(20)32586-5

DOI: $\quad$ https://doi.org/10.1016/j.jclepro.2020.122539

Reference: JCLP 122539

To appear in: Journal of Cleaner Production

Received Date: 18 June 2019

Revised Date: 16 May 2020

Accepted Date: 31 May 2020

Please cite this article as: Nie D, Li H, Qu T, Liu Y, Li C, Optimizing Supply Chain Configuration with Low Carbon Emission, Journal of Cleaner Production, https://doi.org/10.1016/j.jclepro.2020.122539.

This is a PDF file of an article that has undergone enhancements after acceptance, such as the addition of a cover page and metadata, and formatting for readability, but it is not yet the definitive version of record. This version will undergo additional copyediting, typesetting and review before it is published in its final form, but we are providing this version to give early visibility of the article. Please note that, during the production process, errors may be discovered which could affect the content, and all legal disclaimers that apply to the journal pertain.

(c) 2020 Elsevier Ltd. All rights reserved. 


\section{Optimizing Supply Chain Configuration with Low Carbon \\ Emission}

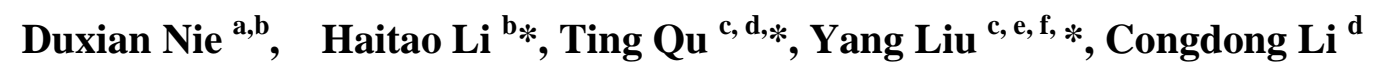

${ }^{a}$ College of Mathematics and Informatics, South China Agricultural University, Guangzhou 510642, PR China

${ }^{\mathrm{b}}$ Supply Chain \& Analytics Department, College of Business Administration, University of Missouri - St. Louis, St. Louis, MO, USA

${ }^{\mathrm{c}}$ School of Intelligent Systems Science and Engineering, Jinan University (Zhuhai Campus), Zhuhai, China

${ }^{\mathrm{d}}$ Institute of Physical Internet, Jinan University (Zhuhai Campus), Zhuhai 519070, PR China

${ }^{\mathrm{e}}$ Department of Management and Engineering, Linköping University, SE-581 83 Linköping, Sweden

${ }^{\mathrm{f}}$ Department of Production, University of Vaasa, 65200 Vaasa, Finland

*Corresponding authors: Haitao Li, lihait@umsl.edu; Ting Qu, quting@jnu.edu.cn, Yang Liu, yang.liu@liu.se 


\section{Author Contributions}

Duxian Nie: Conceptualization, Methodology, Implementation, and Writing

Haitao Li: Methodology, Writing and Editing

Ting Qu: Conceptualization, Data acquisition

Yang Liu: Conceptualization, Data acquisition

Congdong Li: Validating 


\section{Graphical Abstract}

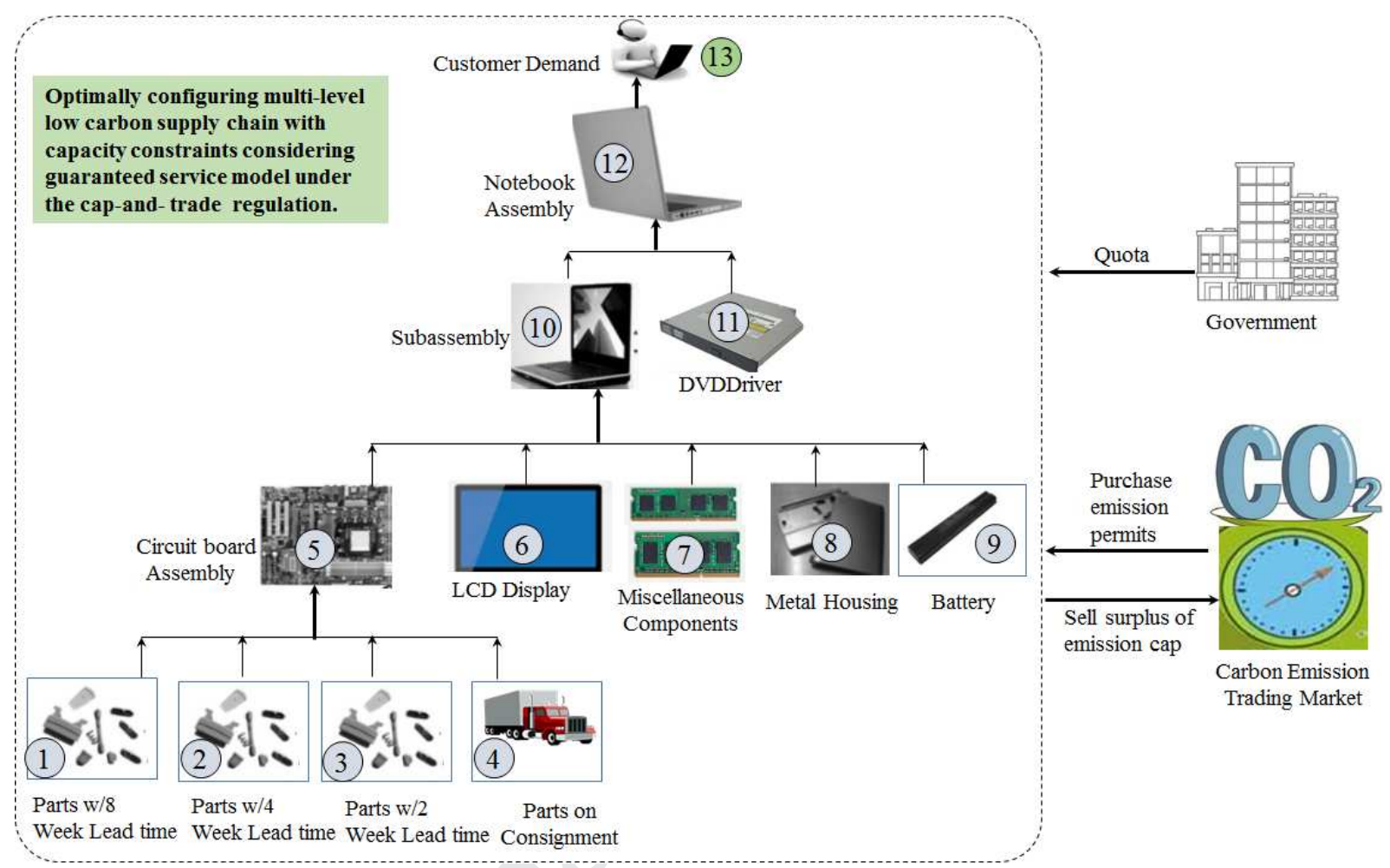




\title{
Optimizing Supply Chain Configuration with Low Carbon Emission
}

\begin{abstract}
We study a new supply chain configuration problem to optimize the amount of carbon emission in the context of a service guarantee modelling framework, called supply chain configuration problem with low carbon emission (SCCP-LCE). The main innovation of our model is the explicit consideration of carbon emission cap and trading price in the supply chain configuration setting with operating capacity. The model is formulated as a mixed-integer nonlinear program (MINLP), and optimally solved by a custom designed dynamic programming algorithm. A case study and computational experiment are performed to examine the behaviour of optimal SCCP-LCE configurations, and the effects of key input parameters: carbon emission cap, trading price, and operating capacity. Our results suggest that government-imposed carbon emission policies, in terms of emission cap and trading price, have significant impacts and interactive effects on the optimal supply chain configuration and performance, including the safety stock cost and carbon emission cost. Our model and methodology offer a new analytical framework to prescribe data-driven decision support for both firms and governmental/environmental agencies to control carbon emission, while achieving optimal business and social benefits.
\end{abstract}

Key words: Supply chain configuration; Dynamic programming; Capacity constraints; Low-carbon supply chain design; Carbon cap and trade

\section{Introduction}

Global warming due to excessive greenhouse gas emission has been and continues to be a grand challenge of humanity. Its detrimental consequences of rising sea levels, frequent occurrence of natural disasters, distinction of precious animal and plant species, all lead to significant economic losses globally (Adams \& Acheampong, 2019). Facing this grand challenge, how to effectively reduce carbon emissions is an important and imperative issue, and has been receiving significant attention from academia, industry and government. From 
the government perspective, more stringent emission regulations (e.g. carbon cap and trading) have been adopted and emission reduction targets have been established. For instance, the Chinese government sets a target of 40\%-45\% emission reduction from that of 2005 by 2020 (Dinan, 2008). From the supply chain operations perspective, carbon emission exists over the entire process of transforming goods to end products (Mao et al.2017; Shaharudin et al.2019). Manufacturing firms and their supply chains are considered to be the most significant source of contribution to carbon emissions (Shaharudin et al., 2019). Over 90 percent of emissions can be found throughout the supply chains of firms (Mao et al., 2017).

Carbon reduction is also directly related to the concept of sustainable supply chain management (SSCM, Carter and Rogers 2008), where sustainability is defined as the integration of environmental, social and economic metrics to achieve long-term economic viability. As pointed out by Awan et al. (2017), achieving sustainability requires implementation of SSCM to address stakeholder's needs, which boils down to offer environment-friendly and low-carbon products to meet market demand while minimizing supply chain cost. A number of recent studies address the reduction of carbon emissions during supply chain operations. For instance, De et al. (2018) study the dynamic ship berth allocation problem considering sustainability issues. Ship routing and container shipping problems are studied by De et al. $(2019,2020)$ to reduce carbon emissions in the maritime transportation setting. Correia et al. (2013) develop a working definition and model for low carbon procurement focusing on public procurement. Böttcher \& Müller (2015) investigate the determinants of measures used by German automotive suppliers to cut carbon emissions, and their impact on performance. Cao et al. (2017) study the impacts of government regulation policies on the production and carbon emission reduction level of a manufacturer. Carbon emissions performance for the logistics industry at the city level is studied by Yang et al. (2019). However, the recent review of Chelly et al. (2019) shows that there is little research on the supply chain system-wide emission reduction.

Our research in this paper was motivated by the needs for the system-wide design and configuration of a supply chain while simultaneously addressing multiple performance metrics of cost, lead time and carbon emission to a manufacturer to achieve sustainability. This calls for the study of a supply chain configuration problem (SCCP). The basic version of 
SCCP determines the selection of available modes of each supply chain node, in conjunction with the level and location of safety stock (inventory positioning), to optimize the system-wide supply chain performance (Graves and Willlam, 2005). A recent survey of (Das and Jharkharia, 2018) indicates that the tactical-level SCCP with low carbon emission consideration is an effective means to achieve multiple dimensions of performance metrics. The addressed problem has applications in various manufacturing industries including electronics, home appliance and computing equipment. For instance, low energy consumption refrigerators and TVs are particularly popular due to their low-carbon and environment-friendly features (Huang et al., 2006). This has profound impacts on the re-design of their corresponding supply chains, while considering enacted laws and carbon emission control policies. Some prominent companies, e.g., Dell and Intel, have been contracting with their suppliers to redesign and reconfigure their supply chains with environmental concerns (Ni and Shu, 2015). Additional complexity arises when government-imposed carbon emission cap can be traded in market (Benjaafar and Daskin, 2013). This has led to new decision needs for supply chain configuration, i.e. which production, transportation (truck, rail, and barge) or sourcing modes to choose. By properly selecting the available modes for a supply chain node, a firm is able to control its emission at the right level, either above the allowed emission cap with a cost, or below the emission cap, which may generate revenue by selling the surplus of emission cap in trading market. Since the available modes often also differ in their lead times and direct costs, selecting the best modes to configure a supply chain network is a non-trivial task.

As we shall elaborate in our literature review, most of the existing research in managing low carbon supply chain focus mainly on the long-term strategic green supply chain network design (cf. Das \& Jharkharia (2018), Chelly et al. (2019) and Shaharudin et al. (2019)), but not the intermedium-term tactical level supply chain configuration decisions. The supply chain configuration literature, on the other hand, has been growing in recent years, but few address it while considering the carbon emission issue. Specifically, firms' mode selection and safety stock placement decisions will be constrained and impacted by the government-imposed carbon emission cap and trading price, but currently there is no study available to take these into consideration in supply chain configuration. In addition, the 
modes for supply chain functions often have trade-offs among lead time, cost, and carbon emission. For example, modes with carbon emission control sometimes requires special equipment or operating procedures, which often results in higher direct cost added and/or longer lead time. It is interesting and necessary to have a modelling framework that is able to explicitly consider the trade-off between carbon emission and other performance metrics such as cost and lead time. Our research in this paper aims to fill this gap. We develop a new optimization model and solution approach to configure a supply chain with the triad performance measures: Lead Time - Cost - Carbon Emission. Our model is capable to configure an environment-friendly supply chain, in terms of the safety stock placement and mode selection decisions, to optimally trade-off lead time, cost and carbon emission under limited capacity of supply chain functions. It provides a vehicle to examine the impacts of carbon emission cap, government policy and regulation via carbon trading price, on the optimal supply chain configuration. We build a new mixed-integer nonlinear programming (MINLP) model for the addressed SCC problem with low carbon emission, which is called SCCP-LCE in the sequel. A custom designed dynamic programming (DP) algorithm is implemented to obtain optimal solutions to SCCP-LCE. A comprehensive computational experiment is performed to examine the impacts of various key parameters on the optimal configuration solutions.

Our work makes the following contributions to the literature. First, we coin a new SCCP-LCE which explicitly optimizes multiple performance metrics of cost, lead time and carbon emission under limited operating capacity. Secondly, a mixed-integer nonlinear programming (MINLP) model is developed for SCCP-LCE, and is optimally solved by a custom designed dynamic programming algorithm. In addition, managerial insights are obtained through a case study and computational experiment. Our model and methodology offer a new analytical framework to prescribe data-driven decision support for both firms and governmental/environmental agencies to control carbon emission, while achieving optimal business and social benefits.

The remainder of our paper is organized as follows. Section 2 reviews the related research literature. Section 3 formally describes the SCCP-LCE problem with its MINLP formulation and a sketch of the DP algorithm. Computational experiment and results are 
presented and discussed in Section 4. Finally, Section 5 draws conclusions and discusses future research opportunities.

\section{Literature Review}

Given the large body of literature on the addressed topic, we structure our review into two main areas: low carbon supply chain design and supply chain configuration (SCC).

\subsection{Low Carbon Supply Chain Design}

This line of research focuses on the strategic supply chain network design while considering low carbon emission requirement and objective. We refer to Das \& Jharkharia (2018), Chelly et al. (2019) and Shaharudin et al. (2019) for comprehensive and updated surveys, and Eskandarpour et al. (2015) and Waltho et al. (2019) for the broader topic of sustainable supply chain design. Notably, Ramudhin et al. (2010) develop a mixed-integer linear programming (MILP) model to minimize the total costs of logistics and carbon emissions. Wang et al. (2011) study the environmental impact of material handling and transportation operations via a multi-objective MILP model. Fahimnia et al. (2015) apply a mixed-integer nonlinear programming (MINLP) model to optimize production and distribution decisions while considering carbon and fuel prices. A bi-objective optimization model is employed by Kuo et al. (2018) to exploit the trade-off between operating cost and carbon emission. Sherafati et al. (2019) consider three metrics in sustainable supply chain network design to maximize the economic, environmental and social benefits.

Table 1 summarizes and compares features of the aforementioned articles in supply chain structure, type of low carbon policy, optimization model, and their contributions. None of them addresses the tactical level decisions involving mode selection or inventory positioning.

Table 1. Summary and comparison of works on low carbon supply chain design.

\begin{tabular}{|c|c|c|c|c|}
\hline References & $\begin{array}{c}\text { Supply chain } \\
\text { structure }\end{array}$ & $\begin{array}{c}\text { Low carbon } \\
\text { policy }\end{array}$ & $\begin{array}{c}\text { Optimization } \\
\text { Model }\end{array}$ & Contributions \\
\hline $\begin{array}{c}\text { Ramudhin et } \\
\text { al.(2010) }\end{array}$ & Multi-level & Carbon trade & MILP & $\begin{array}{l}\text { Develop an integrated model for } \\
\text { sustainable supply chain network } \\
\text { design with carbon trading } \\
\text { markets. }\end{array}$ \\
\hline
\end{tabular}




\begin{tabular}{|c|c|c|c|c|}
\hline $\begin{array}{l}\text { Wang, et } \\
\text { al.(2011) }\end{array}$ & Multi-level & - & MILP & $\begin{array}{l}\text { Introduce a green supply chain } \\
\text { network design model considering } \\
\text { environmental impacts of handling } \\
\text { and transportation operations. }\end{array}$ \\
\hline $\begin{array}{c}\text { Chaabane, et } \\
\text { al.(2012) }\end{array}$ & Closed-loop & Carbon trade & MILP & $\begin{array}{l}\text { Present a mathematical model for } \\
\text { sustainable supply chain design } \\
\text { during product life cycle. }\end{array}$ \\
\hline $\begin{array}{l}\text { Diabat et } \\
\text { al.(2013) }\end{array}$ & Closed-loop & $\begin{array}{l}\text { Carbon cap } \\
\text { and trade }\end{array}$ & MILP & $\begin{array}{l}\text { Study a multi-echelon } \\
\text { multi-commodity facility location } \\
\text { problem with trading price of } \\
\text { carbon emissions. }\end{array}$ \\
\hline $\begin{array}{l}\text { Baud-Lavign } \\
\text { e et al.(2014) }\end{array}$ & Multi-level & Carbon cap & MILP & $\begin{array}{l}\text { Propose a model for carbon } \\
\text { footprint optimization in product } \\
\text { and supply chain design. }\end{array}$ \\
\hline $\begin{array}{l}\text { Fahimnia et } \\
\text { al. (2015) }\end{array}$ & Multi-level & Carbon trade & MINLP & $\begin{array}{l}\text { Present a model to trade-off the } \\
\text { economic and environmental } \\
\text { metrics in production and } \\
\text { distribution planning. }\end{array}$ \\
\hline $\begin{array}{c}\text { Shaw et al. } \\
\text { (2016) }\end{array}$ & Multi-level & $\begin{array}{l}\text { Carbon cap } \\
\text { and trade }\end{array}$ & $\begin{array}{c}\text { Stochastic } \\
\text { MILP }\end{array}$ & $\begin{array}{l}\text { Propose a chance-constrained } \\
\text { green supply chain network design } \\
\text { model addressing carbon emissions } \\
\text { and carbon trading issues. }\end{array}$ \\
\hline $\begin{array}{l}\text { Rahmani \& } \\
\text { Mahoodian } \\
\quad(2017)\end{array}$ & Multi-level & $\begin{array}{l}\text { Carbon cap } \\
\text { and Trade }\end{array}$ & MINLP & $\begin{array}{l}\text { Develop green supply chain } \\
\text { network design model for strategic } \\
\text { and operational phases. }\end{array}$ \\
\hline $\begin{array}{l}\text { Sahebjamnia } \\
\text { et al. (2018) }\end{array}$ & Closed-loop & - & MILP & $\begin{array}{l}\text { Propose a multi-objective } \\
\text { optimization to balance economic, } \\
\text { environmental and social } \\
\text { performance metrics. }\end{array}$ \\
\hline $\begin{array}{l}\text { Kuo et al. } \\
\text { (2018) }\end{array}$ & Multi-level & Carbon Cap & MILP & $\begin{array}{l}\text { Apply a bi-objective optimization } \\
\text { model to tradeoff carbon emissions } \\
\text { and cost. }\end{array}$ \\
\hline $\begin{array}{l}\text { Sherafati et } \\
\text { al. (2019) }\end{array}$ & Multi-level & Carbon Cap & MINLP & $\begin{array}{l}\text { Propose supply chain network } \\
\text { design model for profit } \\
\text { maximization while considering } \\
\text { environmental and social metrics in } \\
\text { less developed regions. }\end{array}$ \\
\hline
\end{tabular}

\subsection{Supply Chain Configuration}

The purpose of SCC is to optimize the selection of available modes of each supply chain node, in conjunction with the level and location of safety stock (inventory positioning), to optimize the system-wide supply chain performance (Graves and Willlam, 2005). The SCC 
problem is built upon an underlying framework known as the guaranteed service model (GSM, Simpson (1958)), where in order to meet uncertain demand and guarantee service or delivery time for the downstream customers, each stage maintains a proper level of base and safety stock. The simple serial chain structure of GSM is generalized to a supply chain network with general structure by (Inderfurth 1991; Inderfurth and Minner, 1998), which leads to the so-called safety stock placement or inventory positioning problem. Magnanti et al. (2006) develop heuristic algorithms for the safety stock placement problem in a general acyclic supply chain network. Li and Jiang (2012) devise a hybrid constraint programming (CP) and genetic algorithm (GA) for the general safety stock placement problem. There are a number of studies on the variants and extensions of GSM in recent years, including combining the GSM with facility location decisions (You and Grossmann 2010, 2011), considering batch ordering and inventory policies (Li et al., 2013), the continuous review inventory policy (Chen and Li, 2015), with evolving forecasts (Schoenmeyr and Graves, 2009), dual sourcing decisions (Klosterhalfen et al., 2014), and inclusion of capacity constraints (Graves and Schoenmeyr, 2016). We refer to (Eruguz et al., 2016) for an updated and comprehensive survey on GSM.

The seminal work of Graves and Willems (2000, 2001, 2005) coins the term supply chain configuration, by addressing the selection of available modes for each supply chain node simultaneously with the safety stock placement problem, to minimize the system-wide total supply chain costs. It provides a framework to optimize the tradeoff between lead time and direct cost added of the available modes. Huang et al. (2005) consider a SCC problem for a platform product to minimize the total supply chain costs, and develop a GA approach. Graves and Willems (2005) present an MINLP formulation for the SCC of an assemble-to-order (ATO) paradigm, and devise an exact dynamic programming (DP) algorithm for a special type of supply chain with the spanning tree structure. Humair and Willems (2006) study the SCC with cluster of commonalities in a spanning tree network. Li and Womer (2008) address the SCC problem with explicit resource constraints of machines and workforce. Qu et al. (2010) study the optimal configuration problem of assembly supply chain and develop a distributed SCC model, which is solved by analytical target cascading. Li and Womer (2012) develop a model and decomposition algorithm for the SCC in the context 
of make-to-order (MTO) manufacturing. Hua and Willems (2016) consider the SCC with outsourcing decisions in the setting of a two-stage serial network. Qu et al. (2017) extend the SCC to study the multiple assembly supply chains in an industrial cluster environment, and develop a hybrid augmented Lagrangian approach for the addressed problem.

The other line of works address the SCC for new products. Notably, Amini and Li (2011) propose a first SCC model for configuring the supply chain of a new product, while considering the new product diffusion process endogenously in the model. Li and Amini (2012) consider the general case of allowing for multiple sourcing in SCC. Further extension of the model is made by Amini and Li (2015) for a new product with dual market structure: the early and the main markets. The work of Negahban and Dehghanimohammadabadi (2018) considers the dynamics of SCC by modelling it a multi-period setting. We refer to Yao and Askin (2019) for a recent survey on this line of research.

There are less than a handful of papers on the SCC with environmental issues. Notably, Brandenburg (2015) studies an SCC problem for a new consumer product with both economic and environmental criteria through a goal programming approach. Their model addresses the selection of facilities/suppliers and the multi-period allocation of physical goods, but does not deal with safety stock placement or inventory positioning decision. Aggarwal (2018) studies a SCC problem for fast-moving consumer products with both economic and environmental criteria. Their model, however, considers production and procurement of the single firm on single stage, but does not handle the selection of facilities/suppliers and the safety stock placement or the inventory positioning decision. Hong et al. (2018) study a SCC problem with carbon emission. Their model imposes a constraint to limit the amount of carbon emission at each node, and includes a term of government subsidy in the objective function, but does not consider the trading value of emission cap surplus, nor the operating capacity of each node.

Table 2 summarizes the characteristics of the aforementioned articles. There is clearly room to leverage the state-of-the-art development in SCC for MLCSC. In particular, most of the existing research works assume unlimited capacity at each stage, which is unrealistic in real life supply chains. In addition, none of the existing models deals with the decision of flexibly choosing to consume the carbon cap or trade it. Our work in this paper aims to fill 
these gaps.

Table 2. Summary and comparison of works on supply chain configuration.

\begin{tabular}{|c|c|c|c|c|}
\hline References & Main Features & Formulation & $\begin{array}{c}\text { Capacity } \\
\text { Constraints }\end{array}$ & Optimal Objective \\
\hline $\begin{array}{c}\text { Grave and } \\
\text { Willem(2005) }\end{array}$ & $\begin{array}{l}\text { First introduction of SCC } \\
\text { based on GSM }\end{array}$ & MINLP & No & Costs \\
\hline $\begin{array}{l}\text { Huang, et } \\
\text { al.(2005) }\end{array}$ & $\begin{array}{l}\text { SCC considering platform } \\
\text { commonality and modularity } \\
\text { and correlation between } \\
\text { different market demands. }\end{array}$ & MINLP & No & Costs \\
\hline Qu et al. ( 2010) & $\begin{array}{l}\text { SCC applying analytical } \\
\text { target cascading (ATC) } \\
\text { to reach consistent condition } \\
\text { for demand }\end{array}$ & ATC & No & Costs \\
\hline $\begin{array}{l}\text { Amini and Li } \\
\text { (2011); Li and } \\
\text { Amini (2012) }\end{array}$ & $\begin{array}{l}\text { Hybrid model of SCC and } \\
\text { new product diffusion with } \\
\text { dynamic demands. } \\
\text { Multiple-sourcing. }\end{array}$ & MINLP & No & Costs \\
\hline $\begin{array}{c}\text { Amin and } \\
\text { Zhang (2013) }\end{array}$ & $\begin{array}{l}\text { Closed-loop SCC via quality } \\
\text { function deployment }\end{array}$ & MILP & No & Costs \\
\hline $\begin{array}{c}\text { Brandenburg } \\
\text { (2015) }\end{array}$ & $\begin{array}{l}\text { SCC considering economical } \\
\text { and environmental factors }\end{array}$ & MILP & No & $\begin{array}{l}\text { Costs and carbon } \\
\text { emission }\end{array}$ \\
\hline $\begin{array}{l}\text { Amini and Li. } \\
\qquad(2015)\end{array}$ & $\begin{array}{l}\text { Dual market assumption. } \\
\text { Capture the dynamics of } \\
\text { demands using Bass Model }\end{array}$ & MINLP & No & Costs \\
\hline $\begin{array}{l}\text { Qu et al. (2015, } \\
\text { 2017); } \\
\text { Nie et al (2019) }\end{array}$ & $\begin{array}{l}\text { SCC considering industrial } \\
\text { cluster, Augmented } \\
\text { Lagrangian coordination } \\
\text { (ALC) and single-period. }\end{array}$ & MINLP/ALC & Yes & Costs \\
\hline $\begin{array}{l}\text { Afrouzy, et al. } \\
\qquad(2016)\end{array}$ & $\begin{array}{l}\text { SCC considering } \\
\text { multi-echelon, multi-product, } \\
\text { multi-period }\end{array}$ & MILP & No & Costs \\
\hline $\begin{array}{l}\text { Negahban and } \\
\text { Dehghanimoham } \\
\text { madabadi(2018) }\end{array}$ & $\begin{array}{l}\text { Determination of SCC with } \\
\text { production sales policies over } \\
\text { multiple planning horizons }\end{array}$ & MINLP & No & Costs \\
\hline Aggarwal (2018) & $\begin{array}{l}\text { Chance constraint green } \\
\text { SCC on single stage }\end{array}$ & MILP/MINLP & Yes & $\begin{array}{c}\text { Costs and carbon } \\
\text { emission }\end{array}$ \\
\hline Hong et al. (2018) & $\begin{array}{l}\text { Impact study of emission } \\
\text { constraint on green product }\end{array}$ & MINLP & No & $\begin{array}{c}\text { Costs and carbon } \\
\text { emission }\end{array}$ \\
\hline This paper & $\begin{array}{l}\text { SCC with carbon emission } \\
\text { cap and trading prices }\end{array}$ & MINLP & Yes & $\begin{array}{l}\text { Supply chain costs and } \\
\text { carbon emission } \\
\text { cost/revenue }\end{array}$ \\
\hline
\end{tabular}




\section{Optimization Model and Method}

Consider a multi-echelon supply chain consisting of a set of stages (nodes) including sourcing raw materials and components, production, semi- and final-assemblies, and distribution. Each stage can be fulfilled through multiple alternative option/modes that differ in cost, lead time and amount of carbon emissions. The carbon emission of each processing stage is limited to a given carbon cap. A stage is allocated with a certain quantity of carbon emission permits, i.e., the carbon cap (Chang et al., 2017). When the carbon emission of a stage exceeds the stage's cap, the firm needs to purchase emission permits in the carbon trading market; on the other hand, surplus of carbon cap can be traded for a revenue. Each stage has a limited capacity of procurement, production or transportation. The SCCP-LCE seeks to find feasible selection of modes, and the amount of safety stock through the inbound and outbound service times, for all the supply chain nodes, that minimize the total supply chain costs (TSC).

Fig. 1 shows an example of SCCP-LCE for a notebook supply chain. The triangle inside a box indicates safety stock level at the corresponding stage to be optimized. The blue bar in a rectangle of a stage represents the carbon emission cap for the corresponding stage. The yellow bar indicates the carbon emission level of a stage to optimized, with the red and green bars representing purchase (cost) and surplus (revenue) of carbon cap, respectively. To put in context, the stages are grouped into three echelons: sourcing, assembly and delivery. 


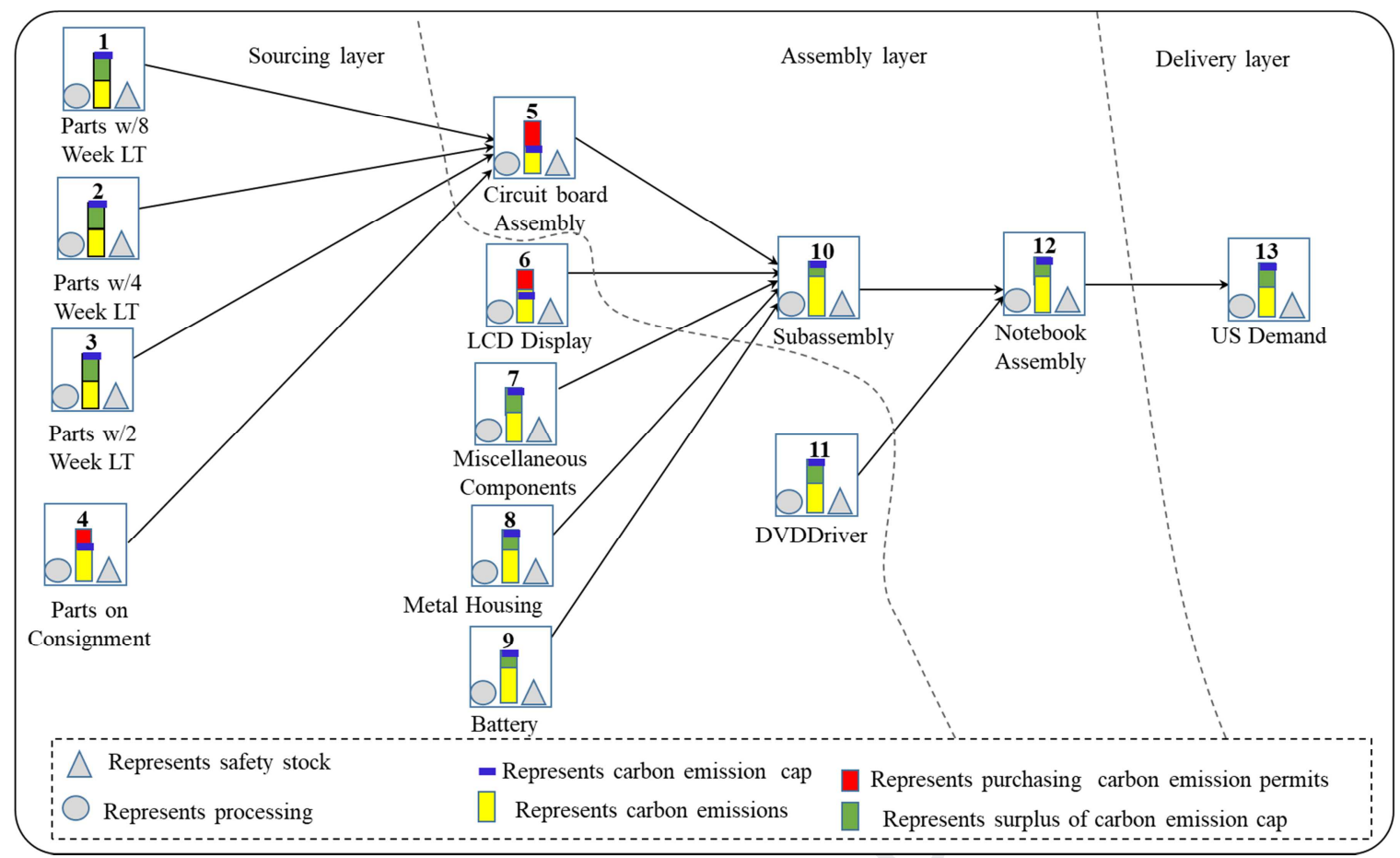

Fig.1. An example of supply chain network (adapted from Graves and Willems 2001).

As in Graves and Willems (2005), the following assumptions are made for the SCCP-LCE. First, we assume that each stage utilizes the periodic inventory review policy, which is a common practice in industry (Silver et al., 1998). Secondly, the external market demand occurs only at the delivery echelon, and the market demand follows normal distribution with mean $\mu$ and variance $\sigma$. The demand at each stage is bounded and independent. Let $W(i)$ be the set of stages that immediately succeed stage $i$, then the demand $\mu_{i}$ and standard deviation $\sigma_{i}$ of stage $i$ can be computed as:

$$
\begin{array}{r}
\mu_{i}=\sum_{j \in W(i)} \rho_{i j} \cdot \mu_{j} \\
\sigma_{i}=\sqrt{\sum_{j \in W(i)}\left(\rho_{i j}\right)^{2}\left(\sigma_{j}\right)^{2}},
\end{array}
$$

where $\rho_{i j}$ is the multiplier in the bill-of-materials (BOM) indicating the units of $i$ needed for producing one unit of $j$. In addition, we assume the firm adopts single-sourcing strategy, such that exactly one mode is selected for each stage.

\subsection{Optimization Model}

A list of sets and parameters are listed below for our formulation.

\section{Sets and Parameters}

$V$ : set of supply chain nodes 
$S$ : set of initial (starting) nodes in the network

$F$ : set of nodes representing the end products

$O_{i}$ : set of available options for chain node $i \in V$

$U(i)$ : set of immediate predecessors of node $i \in V$

$W(i)$ : set of immediate successors of node $i \in V$

$\operatorname{cap}_{i o}$ : maximum capacity of option $o \in O_{i}$ for node $i \in V$. Depending on the actual functionality of node $i, \operatorname{cap}_{i o}$ may represent the capacity of procurement, production, storage, or transportation, accordingly.

$\Omega_{i}$ : maximum allowed carbon emission amount for node $i \in V$. It can be set by an environment regulatory or related government agency.

$p_{i}$ : trading price per unit of carbon emission of node $i \in V$. It can be set by an environment regulatory or related government agency.

$e_{i o}$ : amount of carbon emission of option $o \in O_{i}$ for node $i \in V$. Depending on the actual functionality of node $i, e_{i o}$ is the carbon emission amount of production, storage or transportation, accordingly.

$c_{i o}$ : direct cost added of option $o \in O_{i}$ for node $i \in V$

$t_{i o}$ : lead time of option $o \in O_{i}$ for node $i \in V$

$\alpha_{i}$ : z-value of the corresponding service level for node $i \in V$

$h_{i}$ : stock holding cost rate per time unit of node $i \in V$

$H$ : a scalar for the company's planning horizon

$D_{i}$ : mean of external demand of end node $i \in F$

$\sigma_{i}$ : standard deviation of external demand of end node $i \in F$

$\rho_{i j}$ : multiplier between a pair of nodes $(i, j)$ in the bill-of-materials $(\mathrm{BOM})$, indicating the amount of $i$ needed for one unit of $j$

We define the following decision variables to prescribe the main decisions in the SCCP-LCE on the selection of options/modes and the inbound/outbound service times.

$x_{i o}=1$ if option $o \in O_{i}$ is selected for node $i \in V$

$S T_{i}^{i n} \geq 0$ as the inbound service time of node $i \in V$

$S T_{i}^{\text {out }} \geq 0$ as the outbound service time of node $i \in V$

The following additional derived decision variables are defined for the convenience of 
describing our MINLP formulation.

$T_{i} \geq 0$ : lead time of node $i \in V$

$C_{i} \geq 0$ : direct cost added of node $i \in V$

$\bar{C}_{i} \geq 0$ : cumulative cost of node $i \in V$

$E_{i} \geq 0$ : amount of carbon emission of node $i \in V$

$\omega_{i} \geq 0$ : cost or revenue per unit of emission of node $i \in V$

$\tau_{i} \geq 0$ : net replenishment time of node $i \in V$

$\mathrm{Cap}_{i} \geq 0$ : maximum capacity available allowed for node $i \in V$

\section{Option/Mode Selection}

Constraints (3) (7) model the option selection decisions. Specifically, Constraint (3) ensures that exactly one option is selected for each node due to the single-sourcing assumption. Constraints (4) through (7) compute the lead time, emission amount, operating capacity and direct cost added of each node, respectively, as functions of the mode selection decision variable $x_{i o}$. Constraint (8) computes the cumulative cost of node $i$ as the sum of the $i$ 's direct cost added and the cumulative costs $\bar{C}_{j}$ of all its predecessors $j$.

$$
\begin{gathered}
\sum_{o \in O_{i}} x_{i o}=1, \quad \forall i \in V \\
T_{i}=\sum_{o \in O_{i}} t_{i o} x_{i o}, \quad \forall i \in V \\
E_{i}=\sum_{o \in O_{i}} e_{i o} x_{i o}, \quad \forall i \in V \\
\operatorname{Cap}_{i}=\sum_{o \in O_{i}} \operatorname{cap}_{i o} x_{i o}, \quad \forall i \in V \\
C_{i}=\sum_{o \in O_{i}} c_{i o} x_{i o}, \quad \forall i \in V \\
\bar{C}_{i}=c_{i}+\sum_{j \in U(i)} \rho_{j i} \bar{C}_{j}, \quad \forall i \in V \backslash S
\end{gathered}
$$

Emission cost and/or trading value

The carbon emission cost of a node can be computed as:

$$
\omega_{i}=\left(E_{i}-\Omega_{i}\right) \cdot p_{i}, \quad \forall i \in V
$$

When the amount of emission exceeds the limit, i.e. $E_{i}-\Omega_{i} \geq 0$, a cost is incurred; when the emission amount is below the limit, i.e. $E_{i}-\Omega_{i}<0$, a revenue is generated. Service guarantee requirement 
The following two constraints satisfy the service guarantee requirement. Specifically, Constraint (10) computes the net replenishment time $\tau_{i}$. Constraint (11) ensures that the inbound service time of node $j$ must be no less than the outbound service times of the predecessors of $j$.

$$
\begin{gathered}
\tau_{i}=S T_{i}^{\text {in }}+T_{i}-S T_{i}^{\text {out }}, \quad \forall i \in V \\
S T_{j}^{\text {in }} \geq S T_{i}^{\text {out }}, \quad \forall i \in U(j), j \in V
\end{gathered}
$$

Safety stock under operating capacity

When a stage $i$ has limited operating capacity $\operatorname{Cap}_{i}$, the optimal safety stock at the stage is a piece-wise function of its net replenishment time $\tau_{i}$. Intuitively, if $\tau_{i}$ is smaller than a lower bound $N L B_{i}$, operating at $\operatorname{Cap}_{i}$ for the course of $\tau_{i}$ could be sufficient enough to cover the demand, thus the safety stock would be zero. If $\tau_{i}$ is large enough to exceed certain upper bound $N U B_{i}$, the stage should stock the level given by the demand function, and the capacity constraint does not matter anymore. For our case of normally distributed demand, the lower and upper bounds can be computed as in Graves and Schoenmeyr (2016):

$$
\begin{gathered}
N L B_{i}=-\left(1-\frac{\mu_{i}}{\operatorname{Cap}_{i}}\right)\left(\frac{\sigma_{i}}{\operatorname{Cap}_{i}-\mu_{i}}\right)^{2} \\
N U B_{i}=\left(\frac{\sigma_{i}}{\operatorname{Cap}_{i}-\mu_{i}}\right)^{2}
\end{gathered}
$$

And the safety stock (SS) of node $i$ can be obtained by (14):

$$
S S_{i}=\left\{\begin{array}{cl}
0, & \text { if } \tau_{i}<N L B_{i} \\
\left(\operatorname{Cap}_{i}-\mu_{i}\right) \tau_{i}+\frac{\left(\sigma_{i}\right)^{2}}{\operatorname{Cap}_{i}-\mu_{i}}, & \text { if } N L B_{i} \leq \tau_{i}<N U B_{i} \\
\alpha_{i} \sigma_{i} \sqrt{\tau_{i}}, & \text { if } \quad \tau_{i} \geq N U B_{i}
\end{array}\right.
$$

\section{Objective function}

The objective function is to minimize the total supply chain costs (TSC), which consists of safety stock cost (SSC), pipeline stock cost (PSC), cost of goods sold (COGS) (material cost, procurement cost, production cost, etc.), and emissions trading cost (ETC). The cost structure and relationships among the cost components are delineated in Fig.2. 


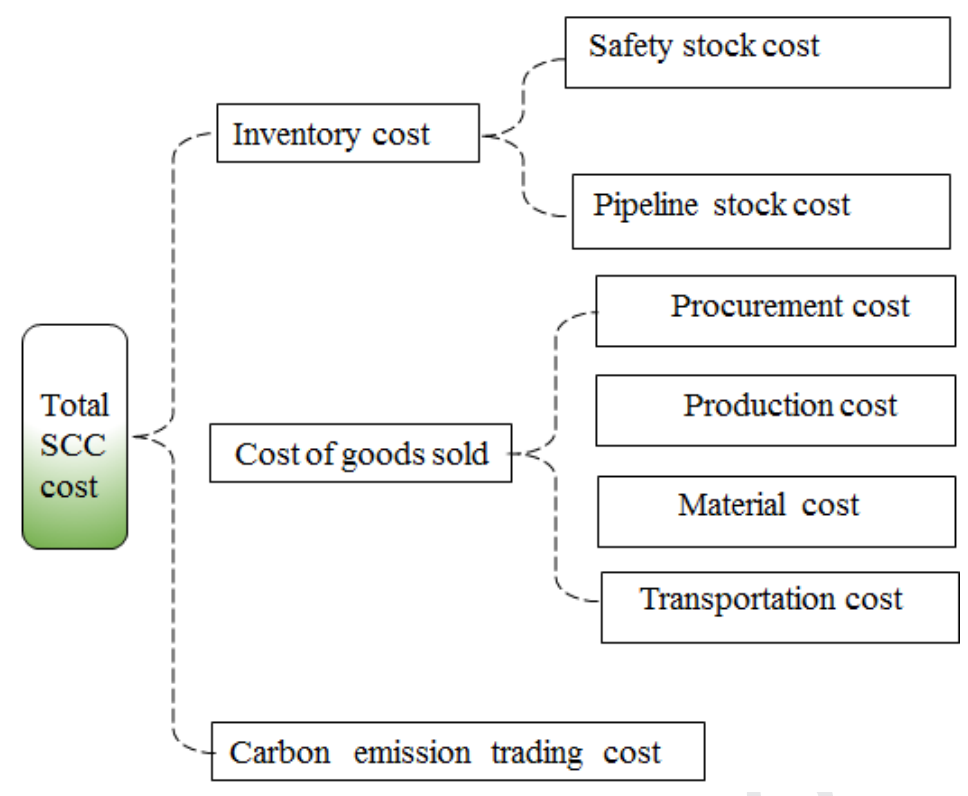

Fig.2. Cost components and structure in the SCCP-LCE model.

According to the Little's Law, work-in-process inventory of the $i^{\text {th }}$ supply chain node is given by $\mu_{i} T_{i}$, thus the PSC can be computed as:

$$
P S C=\sum_{i \in V}\left(\bar{C}_{i}-\frac{c_{i}}{2}\right) \mu_{i} T_{i}
$$

The SSC is obtained by:

$$
S S C=\sum_{i \in V} h_{i} \bar{C}_{i} \cdot S S_{i}
$$

Constraint (17) obtains the COGS:

$$
\text { COGS }=\sum_{i \in V} H c_{i} \mu_{i}
$$

The ETC is the summation of cost of emission for all the nodes:

$$
E T C=\sum_{i \in V} \omega_{i} \mu_{i}
$$

Finally, the objective function is to minimize the TSC:

$$
T S C=S S C+P S C+C O G S+E T C
$$

\subsection{Dynamic Programming Algorithm}

The dynamic programming (DP) approach, originally developed by Bellman (1954), has been widely applied in operations research for applications in operations and supply chain management for decades. It was first employed to obtain optimal solutions to the multi-echelon safety stock placement problem, a sub-problem of SCC, by Graves and 
Willems (2000). Since then, DP algorithm has been successfully employed to solve various SCCs with different supply chain structures and features (Graves and Willems 2005; Humair and Willems 2006; Chen and Li 2015; Graves and Schoenmeyr 2016; Kumar and Aouam 2018). In this paper, we design and implement a first DP algorithm for the SCCP-LCE. Comparing with various problem-specific heuristics or metaheuristics, the advantage of using DP is its ability to provide optimal solutions, which provides a vehicle to obtain managerial insights about the optimal supply chain configuration solution and policies for dealing with carbon emission concerns.

Let $N=|V|$ and the subset $N_{i}$ of nodes $\{1,2, \ldots, i\}, i \in N_{i}$, which are connected to $i$ with node set $\{1,2, \ldots, i\}$, is defined and can be determined by: $N_{i}=\{i\} \bigcup\{h: h \in U(i)\} \bigcup\{h: h \in W(i)\}$. Meanwhile, functions $f_{i}\left(C, S T_{i}^{\text {out }}\right)$, $g_{i}\left(c c, S T_{i}^{i n}\right)$ are defined as the minimum cost for the SCC in the sub-system with node set $N_{i}$ when node $i$ 's parent from its upstream and downstream, respectively. And $r_{i k}\left(S T_{i}^{i n}, C c_{1}, c c_{2}, S T_{i}^{\text {out }}\right)$ is defined as the cost function for the sub-system with node set $N_{i}$. Let $C$ be the cumulative unit cost at stage $i, c c_{1}$ and $c c_{2}$ represent the cumulative unit cost of node $i$ 's parent from its upstream, and the cumulative cost for all of the other upstream adjacent stages, respectively. $r_{i k}$ can be computed as follows:

$$
\begin{gathered}
r_{i k}\left(S T_{i}^{i n}, c c_{1}, c c_{2}, S T_{i}^{\text {out }}\right)=h_{i} S S_{i} C+H c_{i k} \mu_{i}+ \\
h_{i}\left(C-\frac{c_{i k}}{2}\right) T_{i k} \mu_{i}+\mu_{i} \omega_{i}+ \\
\sum_{h: h \in U(i)} g_{h}\left(C, S T_{h}^{o u t}\right)+\min _{\sum_{h: h \in U(i)} c_{h}=c c_{2}}\left\{\sum_{h: h \in U(i)} f_{h}\left(c_{h}, S T_{h}^{i n}\right)\right\},
\end{gathered}
$$

where $C=c c_{1},+c c_{2}+c_{i k}, k=o$. The first four terms represent the safety stock cost, cost of goods sold, pipeline stock cost and the carbon emission trading value at stage $i$. The last two terms can be obtained by solving the following optimal problems:

$$
\begin{gathered}
f_{i}\left(C, S T_{i}^{\text {out }}\right)=\min _{k, S T_{i}^{i n}}\left\{r_{i k}\left(S T_{i}^{\text {in }}, 0, C-c_{i k}, S T_{i}^{\text {out }}\right)\right\} \\
\text { s.t. } \max \left(0, S T_{i}^{\text {out }}-T_{i k}\right) \leq S T_{i}^{\text {in }} \leq G_{i}-T_{i k} \\
1 \leq k \leq O_{i}, S T_{i}^{i n} \geq 0 \text { and integer } \\
0 \leq \mu_{i}<\operatorname{Cap}_{i}
\end{gathered}
$$




$$
\begin{gathered}
g_{i}\left(c c_{1}, S T_{i}^{i n}\right)=\min _{k, c c_{2}, S T_{i}^{\text {out }}}\left\{r_{i k}\left(S T_{i}^{\text {in }}, c c_{1}, c c_{2}, S T_{i}^{\text {out }}\right)\right\} \\
\text { s.t. } 1 \leq k \leq O_{i}, S T_{i}^{\text {out }} \geq 0 \text { and integer } \\
0 \leq \mu_{i}<\operatorname{Cap}_{i},
\end{gathered}
$$

where $G_{i}$ represents node $i$ 's maximum replenishment time, which is defined as:

$G_{i}=\max \left\{T_{i k} \mid k: k \in O_{i}\right\}+\max \left\{G_{h} \mid h: h \in U(i)\right\}$. The DP procedure follows that of Graves and Willems (2005).

\section{Computational Study and Results}

The purpose of our computational study is to demonstrate the behaviour of optimal solutions to SCCP-LCE, and to examine the impact of key input parameters on the optimal configuration by conducting a comprehensive computational experiment.

\subsection{A Numerical Example}

Consider the example of a notebook supply chain as shown in Figure 1. Table 3 lists multiple available options (modes) of each stage that differ in lead time, direct cost added, carbon emission and capacity available. We assume that controlling carbon emission consumes more fuels, thus generally incurs higher direct cost added. We set the service level $\alpha_{i}=98 \%$ (i.e. $Z=2.06)$ and the inventory holding cost rate $h_{i}=40 \%$ for each stage. The external market demand is assumed to follow normal distribution with mean of 125 and standard deviation of 80. Table 4 shows cap $\Omega_{i}$ on the amount of carbon emission and its trading price $p_{i}$ at each stage as in Qu et al. (2010). The DP algorithm was coded in Matlab. All the computations

\begin{tabular}{|c|c|c|c|c|c|c|}
\hline Index & Stage name & Option & $\begin{array}{c}\text { Lead time } \\
\text { (days) }\end{array}$ & $\begin{array}{l}\text { Direct Cost Added } \\
\text { (\$) }\end{array}$ & $\begin{array}{c}\text { Carbon emission } \\
\text { (tons) }\end{array}$ & $\begin{array}{c}\text { Capacity constraint } \\
\text { (units) }\end{array}$ \\
\hline \multirow[t]{4}{*}{1} & \multirow{4}{*}{$\begin{array}{l}\text { Parts w/8 week } \\
\text { LT }\end{array}$} & 1 & 40 & 130.00 & 290 & 184 \\
\hline & & 2 & 20 & 133.25 & 250 & 257 \\
\hline & & 3 & 10 & 134.91 & 230 & 152 \\
\hline & & 4 & 0 & 136.59 & 180 & 163 \\
\hline \multirow[t]{3}{*}{2} & \multirow{3}{*}{$\begin{array}{l}\text { Parts w/4 week } \\
\text { LT }\end{array}$} & 1 & 20 & 200.00 & 450 & 214 \\
\hline & & 2 & 10 & 202.50 & 410 & 252 \\
\hline & & 3 & 0 & 205.03 & 268 & 161 \\
\hline \multirow[t]{2}{*}{3} & \multirow{2}{*}{$\begin{array}{l}\text { Parts w/2 week } \\
\text { LT }\end{array}$} & 1 & 10 & 155.00 & 275 & 236 \\
\hline & & 2 & 0 & 156.93 & 210 & 154 \\
\hline
\end{tabular}
were performed on a $\mathrm{PC}$ with $2.5 \mathrm{GHz} \mathrm{CPU}$ and $4 \mathrm{~GB}$ RAM.

Table 3. Available options for each supply chain stage. 


\begin{tabular}{|c|c|c|c|c|c|c|}
\hline 4 & $\begin{array}{l}\text { Parts on } \\
\text { Consignment }\end{array}$ & 1 & 0 & 200.00 & 254 & 279 \\
\hline \multirow[t]{2}{*}{5} & \multirow{2}{*}{$\begin{array}{l}\text { CircuitBoard } \\
\text { Assembly }\end{array}$} & 1 & 20 & 120.00 & 287 & 153 \\
\hline & & 2 & 5 & 150.00 & 195 & 203 \\
\hline \multirow[t]{2}{*}{6} & \multirow[t]{2}{*}{ LCD Display } & 1 & 60 & 300.00 & 460 & 157 \\
\hline & & 2 & 5 & 350.00 & 340 & 212 \\
\hline 7 & $\begin{array}{l}\text { Miscellaneous } \\
\text { Components }\end{array}$ & 1 & 30 & 200.00 & 165 & 250 \\
\hline \multirow[t]{2}{*}{8} & \multirow[t]{2}{*}{ Metal Housing } & 1 & 70 & 225.00 & 375 & 260 \\
\hline & & 2 & 30 & 240.00 & 265 & 158 \\
\hline \multirow[t]{2}{*}{9} & \multirow[t]{2}{*}{ Battery } & 1 & 60 & 40.00 & 270 & 234 \\
\hline & & 2 & 20 & 45.00 & 195 & 148 \\
\hline \multirow[t]{2}{*}{10} & \multirow[t]{2}{*}{ Subassembly } & 1 & 5 & 120.00 & 245 & 155 \\
\hline & & 2 & 2 & 132.00 & 200 & 272 \\
\hline \multirow[t]{2}{*}{11} & \multirow[t]{2}{*}{ DVD Driver } & 1 & 40 & 15.00 & 340 & 305 \\
\hline & & 2 & 5 & 16.50 & 255 & 160 \\
\hline 12 & $\begin{array}{l}\text { NotebookB } \\
\text { Assembly }\end{array}$ & 1 & 1 & 30.00 & 228 & 267 \\
\hline \multirow[t]{2}{*}{13} & \multirow{2}{*}{$\begin{array}{l}\text { US } \\
\text { demand-notebook } \\
\text { B }\end{array}$} & 1 & 5 & 12.00 & 210 & 158 \\
\hline & & 2 & 1 & 20.00 & 128 & 241 \\
\hline
\end{tabular}

Table 4. Carbon emission constraints and carbon cap trading price.

\begin{tabular}{lccccccccccccc}
\hline Stage Index & 1 & 2 & 3 & 4 & 5 & 6 & 7 & 8 & 9 & 10 & 11 & 12 & 13 \\
\hline $\begin{array}{l}\text { Carbon emission } \\
\text { constraints(tons) }\end{array}$ & 280 & 410 & 220 & 260 & 230 & 420 & 170 & 310 & 200 & 210 & 260 & 230 & 130 \\
$\begin{array}{l}\text { Carbon trading } \\
\text { price }(\$ / \text { tons }) p_{i}\end{array}$ & 6 & 6 & 6 & 6 & 6 & 6 & 6 & 6 & 6 & 6 & 6 & 6 & 6 \\
\hline
\end{tabular}

The optimal configurations, with and without capacity constraints, are presented in Table 5. The capacity constrained case incurs slightly higher total supply chain cost (TSC), due to higher safety stock level and safety stock cost (SSC). Both cases prescribe the same (positive) amount of emission trading cost for buying the emission cap. Although the option selections only differ for Stage 1, capacity constraints have significantly impacts on the outbound service time $\left(S T_{i}^{\text {out }}\right)$. Most stages quote significantly smaller $S T_{i}^{\text {out }}$ in the capacity constrained case, which results in higher level and cost of safety stock.

Table 5. Optimal configurations of the base case.

\begin{tabular}{llcccc}
\hline \multirow{2}{*}{ Index } & \multirow{2}{*}{ Stage name } & \multicolumn{2}{c}{ With capacity constraints } & \multicolumn{2}{c}{ Without capacity constraints } \\
\cline { 3 - 6 } & & $o$ & $S T_{i}^{\text {out }}$ & $o$ & $S T_{i}^{\text {out }}$ \\
\hline 1 & Parts w/8 week LT & 4 & 2 & 3 & 10 \\
\hline
\end{tabular}




\begin{tabular}{|c|c|c|c|c|c|}
\hline 2 & Parts w/4 week LT & 3 & 2 & 3 & 0 \\
\hline 3 & Parts w/2 week LT & 2 & 2 & 2 & 0 \\
\hline 4 & Parts on Consignment & 1 & 1 & 1 & 0 \\
\hline 5 & CircuitBoard Assembly & 1 & 24 & 1 & 30 \\
\hline 6 & LCD Display & 1 & 24 & 1 & 30 \\
\hline 7 & Miscellaneous Components & 1 & 24 & 1 & 30 \\
\hline 8 & Metal Housing & 2 & 24 & 2 & 30 \\
\hline 9 & Battery & 2 & 22 & 2 & 20 \\
\hline 10 & Subassembly & 2 & 27 & 2 & 32 \\
\hline 11 & DVD Driver & 2 & 7 & 2 & 5 \\
\hline 12 & NotebookB Assembly & 1 & 29 & 1 & 33 \\
\hline 13 & US demand-notebook B & 2 & 0 & 2 & 0 \\
\hline \multicolumn{2}{|c|}{ Safety stock level } & & \multicolumn{2}{|c|}{2713.719} & 1877.617 \\
\hline \multicolumn{2}{|c|}{$\operatorname{SSC}(\$)$} & & \multicolumn{2}{|c|}{851104} & $\begin{array}{r}810440.3 \\
2778024\end{array}$ \\
\hline $\begin{array}{r}\operatorname{PSC}(\$) \\
\operatorname{COGS}(\$)\end{array}$ & & & \multicolumn{2}{|c|}{81092250} & 81016650 \\
\hline \multicolumn{2}{|c|}{$\operatorname{ETC}(\$)$} & & & & 2430000 \\
\hline \multicolumn{2}{|c|}{$\operatorname{TSC}(\$)$} & & \multicolumn{2}{|c|}{82225939} & 82175114 \\
\hline
\end{tabular}

We now show the relationship between optimal safety stock level and net replenishment time under different demand variations in Fig. 3. The optimal level of safety stock increases when the market is more risky, i.e., more demand variation. The capacitated cases opt to keep more safety stock than their uncapacitated counterpart, although the difference diminishes when demand variation is small enough. It is important to note that when net replenishment time is negative, the uncapacitated cases do not keep any safety stock, because arbitrarily large quantity can be fulfilled. The capacitated cases, however, may incur certain amount of safety stock according to (14). 


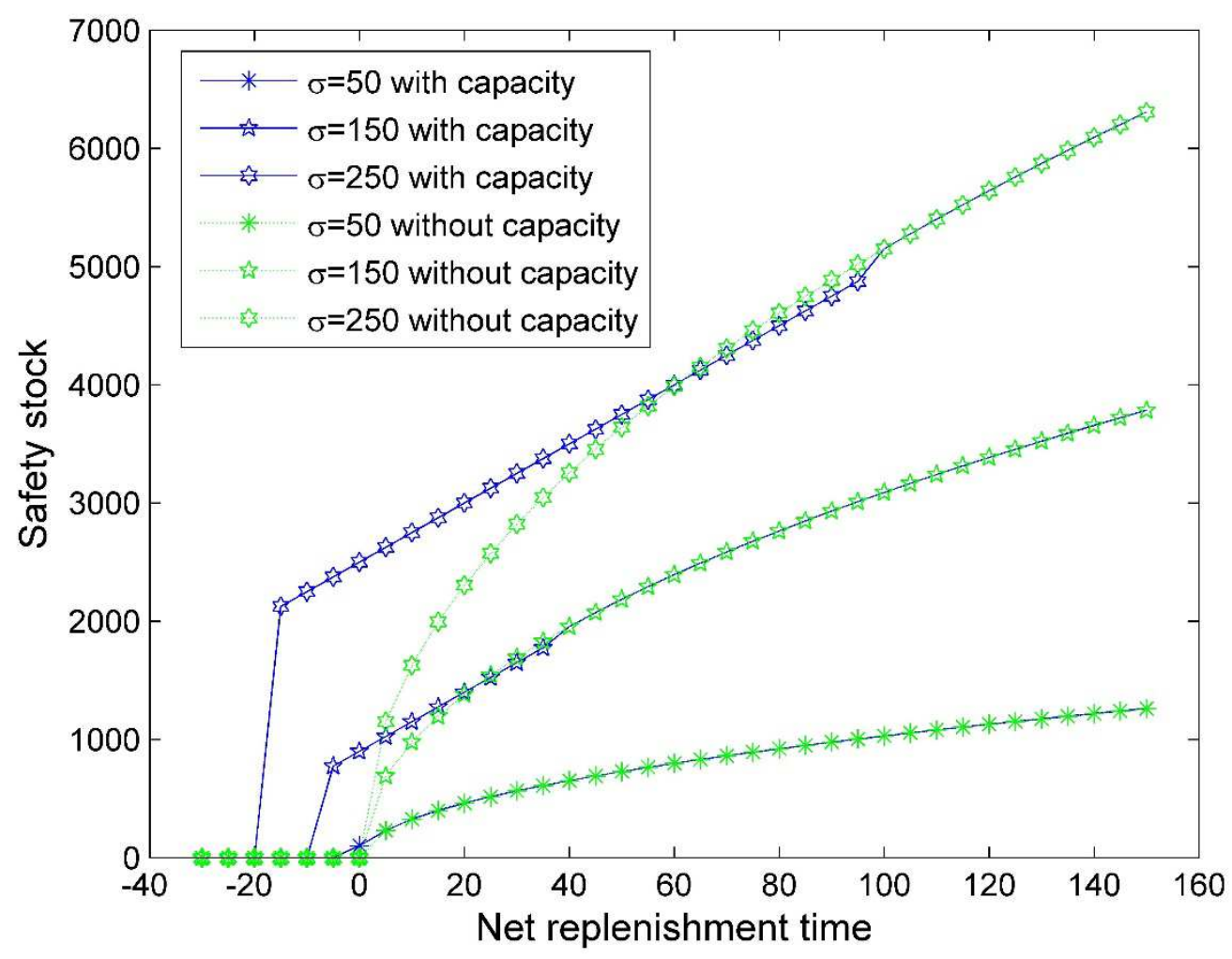

Fig. 3. Optimal safety stock level with different net replenishment times and demand variances.

Sensitivity analysis is performed to further examine the effect of capacity. We assume a base capacity cap of 150 , and systematically change the ratio of capacity in the set $\{0.85$, $0.9,0.95,1,1.5,2,2.5\}$, such that the resulting capacity in each instance is no less than the mean demand of 125. Fig. 4 shows that less available capacity generally increases the optimal level of safety stock, and tends to keep more safety stock when the net replenishment time is negative. Specifically, the curve of 0.85 cap renders a capacity of 127.5 , which is slightly higher than the mean demand of 125 . In order to meet the target service level under the demand variation, significantly higher safety stock is needed than those with other capacity levels. In addition, the optimal safety stock level does not vary when the available capacity is large enough, i.e. greater than $1.63 \mathrm{cap}$, or the surplus capacity is greater than the threshold value $1.5 \sigma=120$ as shown in (Sitompul et al., 2008). 


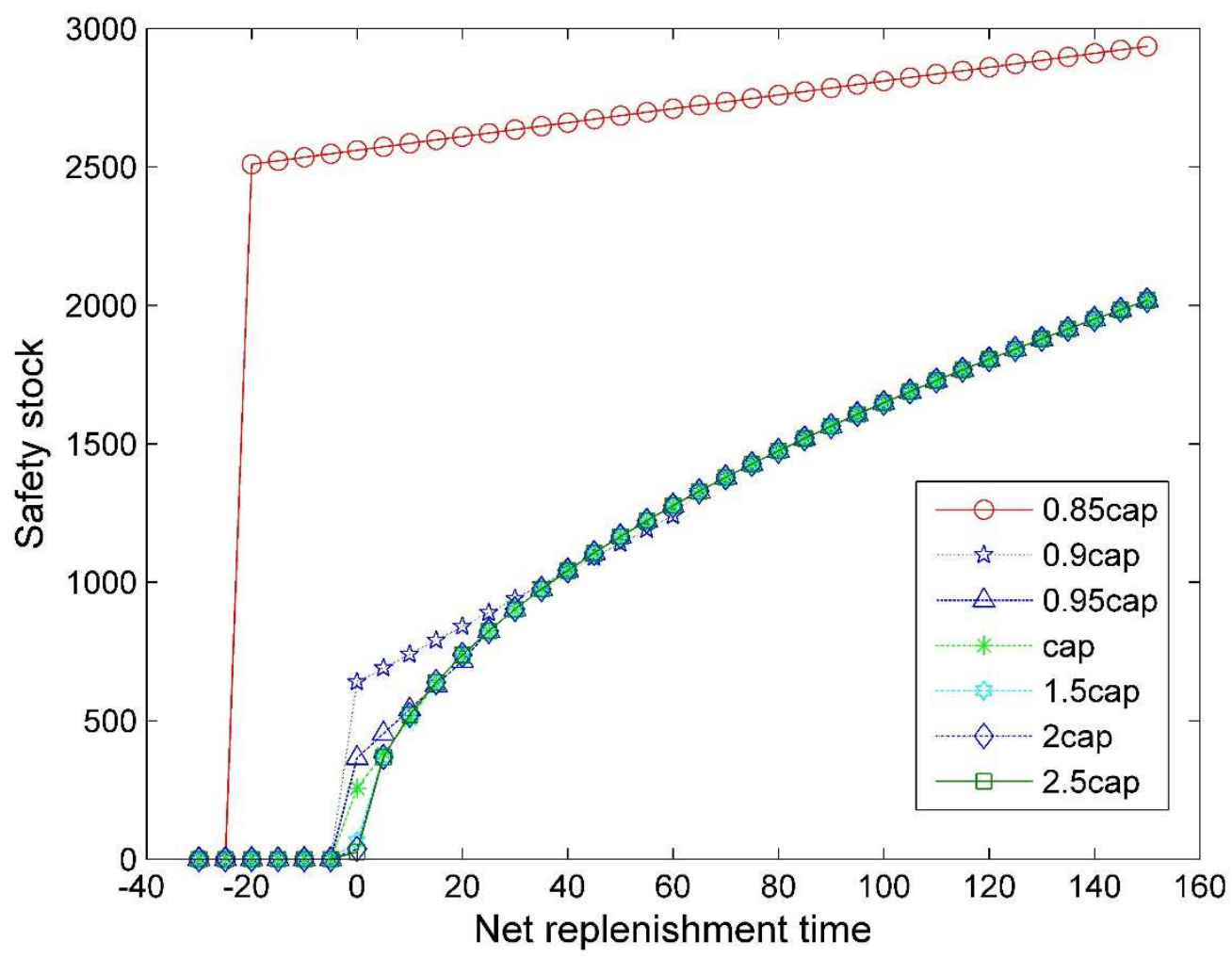

Fig. 4. Optimal safety stock level with different net replenishment times and capacity constraints

The coefficient of carbon emission limit $\Omega_{i}$ of each stage is systematically reduced from $100 \%$ to $40 \%$ by $10 \%$. Table 6 shows the optimal configuration for each case. One observes that as the carbon emission cap becomes tighter, the optimal configuration of each stage tends to choose more costly options with longer lead time and more carbon emission.

Table 6. SCC results with different carbon emission caps.

\begin{tabular}{|c|c|c|c|c|c|c|c|c|c|c|c|c|c|c|}
\hline \multirow{2}{*}{$\begin{array}{l}\text { Stage } \\
\text { index }\end{array}$} & \multicolumn{2}{|r|}{$\overline{\Omega_{i}}$} & \multicolumn{2}{|c|}{$0.9 \Omega_{i}$} & \multicolumn{2}{|c|}{$0.8 \Omega_{i}$} & \multicolumn{2}{|c|}{$0.7 \Omega_{i}$} & \multicolumn{2}{|c|}{$0.6 \Omega_{i}$} & \multicolumn{2}{|c|}{$0.5 \Omega_{i}$} & \multicolumn{2}{|c|}{$0.4 \Omega_{i}$} \\
\hline & $o$ & $S T_{i}^{\text {out }}$ & $o$ & $S T_{i}^{\text {out }}$ & $o$ & $S T_{i}^{\text {out }}$ & $o$ & $S T_{i}^{\text {out }}$ & $o$ & $S T_{i}^{\text {out }}$ & $o$ & $S T_{i}^{\text {out }}$ & $o$ & $S T_{i}^{\text {out }}$ \\
\hline 1 & 4 & 2 & 4 & 2 & 4 & 2 & 4 & 2 & 1 & 11 & 1 & 11 & 1 & 11 \\
\hline 2 & 3 & 2 & 3 & 2 & 3 & 2 & 3 & 2 & 2 & 11 & 2 & 11 & 2 & 11 \\
\hline 3 & 2 & 2 & 2 & 2 & 1 & 10 & 2 & 2 & 1 & 11 & 1 & 11 & 1 & 11 \\
\hline 4 & 1 & 1 & 1 & 1 & 1 & 1 & 1 & 1 & 1 & 1 & 1 & 1 & 1 & 1 \\
\hline 5 & 1 & 24 & 1 & 24 & 1 & 32 & 1 & 24 & 1 & 33 & 1 & 33 & 1 & 33 \\
\hline 6 & 1 & 24 & 1 & 30 & 1 & 32 & 1 & 26 & 1 & 33 & 1 & 33 & 1 & 33 \\
\hline 7 & 1 & 24 & 1 & 30 & 1 & 31 & 1 & 26 & 1 & 31 & 1 & 31 & 1 & 31 \\
\hline 8 & 2 & 24 & 2 & 30 & 1 & 32 & 1 & 26 & 1 & 33 & 1 & 33 & 1 & 33 \\
\hline 9 & 2 & 22 & 1 & 30 & 1 & 32 & 1 & 26 & 1 & 33 & 1 & 33 & 1 & 33 \\
\hline
\end{tabular}




\begin{tabular}{lllllllllllllll}
10 & 2 & 27 & 1 & 37 & 1 & 39 & 1 & 33 & 1 & 40 & 1 & 40 & 1 & 40 \\
11 & 2 & 7 & 1 & 37 & 1 & 39 & 1 & 33 & 1 & 40 & 1 & 40 & 1 & 40 \\
12 & 1 & 29 & 1 & 39 & 1 & 41 & 1 & 35 & 1 & 42 & 1 & 42 & 1 & 42 \\
13 & 2 & 0 & 2 & 0 & 2 & 0 & 2 & 0 & 2 & 0 & 2 & 0 & 2 & 0 \\
\hline
\end{tabular}

We now vary the carbon trading price of each stage by multiplying the base $p_{i}$ with a coefficient in the set $\{0.125,0.25,0.5,1,2,4,8\}$. As shown in Table 7 , when carbon cap trading price increases, optimal configuration tends to choose options with less emission and each stage's quoted outbound service time decreases.

Table 7. SCC results with different carbon trading price

\begin{tabular}{|c|c|c|c|c|c|c|c|c|c|c|c|c|c|c|}
\hline \multirow{2}{*}{$\begin{array}{l}\text { Stage } \\
\text { index }\end{array}$} & \multicolumn{2}{|c|}{$0.125 p_{i}$} & \multicolumn{2}{|c|}{$\overline{0.25 p_{i}}$} & \multicolumn{2}{|c|}{$0.5 p_{i}$} & \multicolumn{2}{|c|}{$\overline{p_{i}}$} & \multicolumn{2}{|c|}{$2 p_{i}$} & \multicolumn{2}{|c|}{$4 p_{i}$} & \multicolumn{2}{|c|}{$8 p_{i}$} \\
\hline & $o$ & $S T_{i}^{\text {out }}$ & o & $S T_{i}^{\text {out }}$ & $o$ & $S T_{i}^{\text {out }}$ & $o$ & $S T_{i}^{\text {out }}$ & $o$ & $S T_{i}^{\text {out }}$ & $o$ & $S T_{i}^{\text {out }}$ & $o$ & $S T_{i}^{\text {out }}$ \\
\hline 1 & 4 & 2 & 4 & 2 & 4 & 2 & 4 & 2 & 4 & 2 & 4 & 0 & 4 & 0 \\
\hline 2 & 3 & 2 & 3 & 2 & 3 & 2 & 3 & 2 & 3 & 2 & 3 & 0 & 3 & 0 \\
\hline 3 & 2 & 2 & 2 & 2 & 2 & 2 & 2 & 2 & 2 & 2 & 2 & 0 & 2 & 0 \\
\hline 4 & 1 & 1 & 1 & 1 & 1 & 1 & 1 & 1 & 1 & 1 & 1 & 0 & 1 & 0 \\
\hline 5 & 1 & 24 & 1 & 24 & 1 & 24 & 1 & 24 & 2 & 8 & 2 & 5 & 2 & 6 \\
\hline 6 & 1 & 24 & 1 & 24 & 1 & 32 & 1 & 24 & 1 & 8 & 2 & 5 & 2 & 6 \\
\hline 7 & 1 & 24 & 1 & 24 & 1 & 31 & 1 & 24 & 1 & 8 & 1 & 5 & 1 & 6 \\
\hline 8 & 1 & 24 & 1 & 24 & 2 & 32 & 2 & 24 & 2 & 8 & 2 & 5 & 2 & 6 \\
\hline 9 & 1 & 24 & 1 & 24 & 2 & 22 & 2 & 22 & 2 & 8 & 2 & 5 & 2 & 6 \\
\hline 10 & 1 & 31 & 1 & 31 & 2 & 35 & 2 & 27 & 2 & 11 & 2 & 7 & 2 & 9 \\
\hline 11 & 2 & 7 & 2 & 7 & 2 & 7 & 2 & 7 & 2 & 7 & 2 & 7 & 2 & 7 \\
\hline 12 & 1 & 33 & 1 & 33 & 1 & 37 & 1 & 29 & 1 & 13 & 1 & 9 & 1 & 11 \\
\hline 13 & 2 & 0 & 2 & 0 & 2 & 0 & 2 & 0 & 2 & 0 & 2 & 0 & 2 & 0 \\
\hline
\end{tabular}

\subsection{Computational Experiment}

A comprehensive computational experiment is designed and performed to further examine the impacts of key parameters and their interactive effects. We focus on three parameters: carbon emission cap, trading price, and capacity constraints, which represent all the new features of SCCP-LCE studied in this paper. Their values and expected effects (hypotheses) are stated in Table 8. These values are chosen such that the optimal solutions demonstrate meaningful behavior. Larger values of coefficient of capacity are not considered, because they do not significantly change the optimal configuration as evident in Fig. 4. A total of $7 \times 7 \times 4=196$ instances are generated and solved to optimality via our DP algorithm. 
Table 8. Parameters controlled in the experiment and their values.

\begin{tabular}{|l|l|l|}
\hline Parameters & Values & Expected effects \\
\hline Coefficient of carbon cap & $\{0.85,0.9,0.95,1,1.5,2,2.5\}$ & $\begin{array}{l}\text { On safety stock, carbon trade costs, and } \\
\text { interactive effect }\end{array}$ \\
\hline Coefficient of trading price & $\{0.125,0.25,0.5,1,2,4,8\}$ & $\begin{array}{l}\text { On safety stock, carbon trade cost, and } \\
\text { interactive effect }\end{array}$ \\
\hline Coefficient of capacity & $\{0.85,0.9,0.95,1\}$ & On safety stock and carbon trade cost \\
\hline
\end{tabular}

\subsubsection{Effects of Carbon Emission Cap}

The optimal safety stock level tends to go up when the carbon emission cap increases as shown in Fig. 5(a). This is consistent with the finding from Table 6 that a stage tends to quote shorter outbound service time, which leads to higher level of safety stock. Fig. 5(b) shows that the average optimal safety stock cost, however, goes down when the carbon emission cap is less tight, and the relationship appears to be nonlinear: it is initially flat, then at around coefficient of 0.8 , it becomes significantly steeper suggesting that safety stock cost becomes more sensitive with the higher carbon cap. This is because increasing carbon cap also affects optimal option selection: less costly options with shorter lead time tend to be selected as in Table 6, which will offset the effect of shorter outbound service times, and results decrease of average SSC. Insight 1 summarizes the above findings.

INSIGHT 1. Higher carbon emission cap will tend to increase the level of safety stock, but lead to lower safety stock cost.

Fig. 6 shows that when carbon cap is tight, a firm opts to buy emission caps from the trading market, thus incur (positive) carbon trading cost. As carbon cap increases, a firm is able to have surplus of cap to generate revenue, which results in negative average carbon trading cost. Again, such relationship also appears to be nonlinear, which would not be intuitive to obtain without an optimization approach. Insight 2 follows.

INSIGHT 2. Increasing carbon emission cap will decrease carbon trading cost; when the cap is large enough, it will result in revenue of carbon trading for a firm. Such relationship is nonlinear, the i.e. the rate of change of trading cost is not constant with the change of cap. 


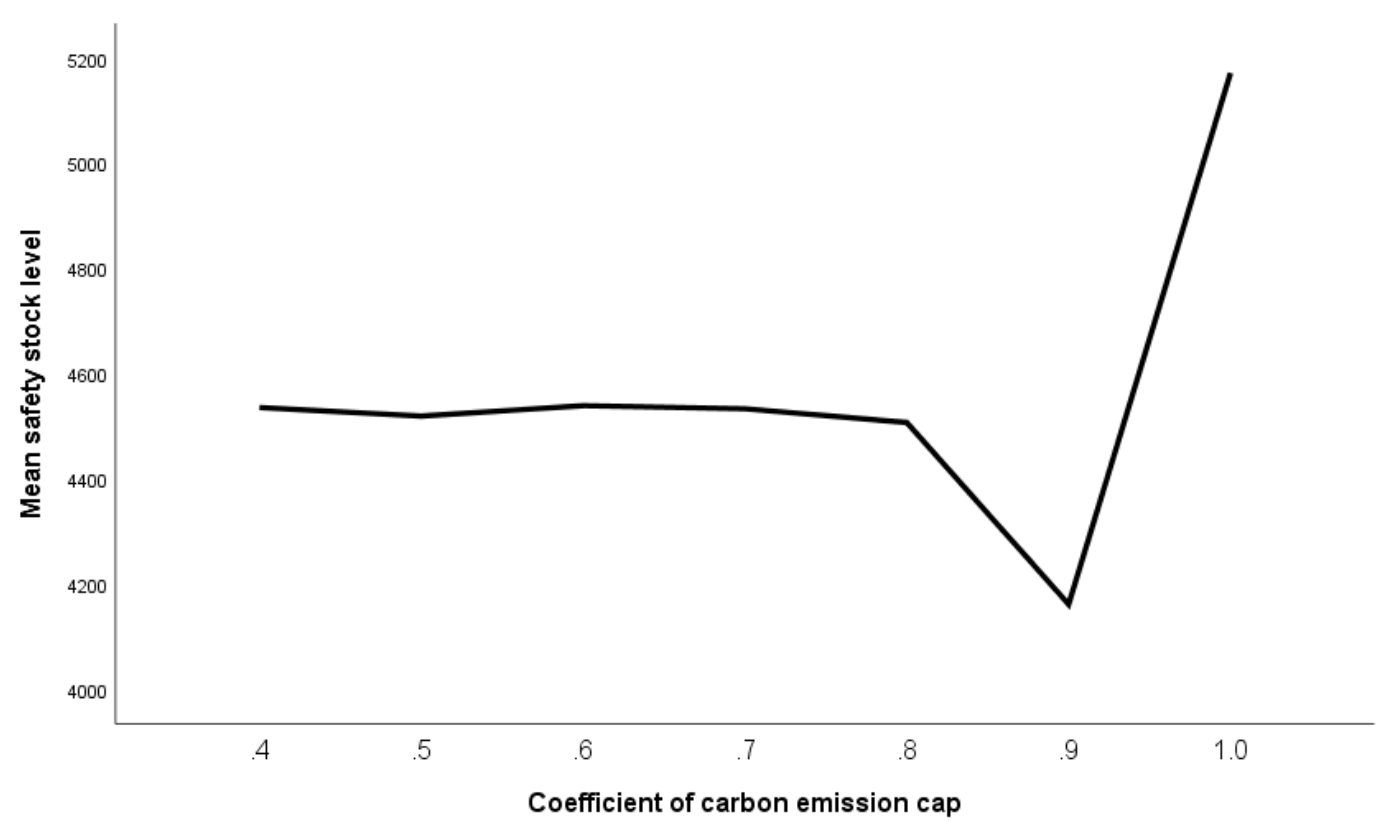

(a) Average safety stock level.

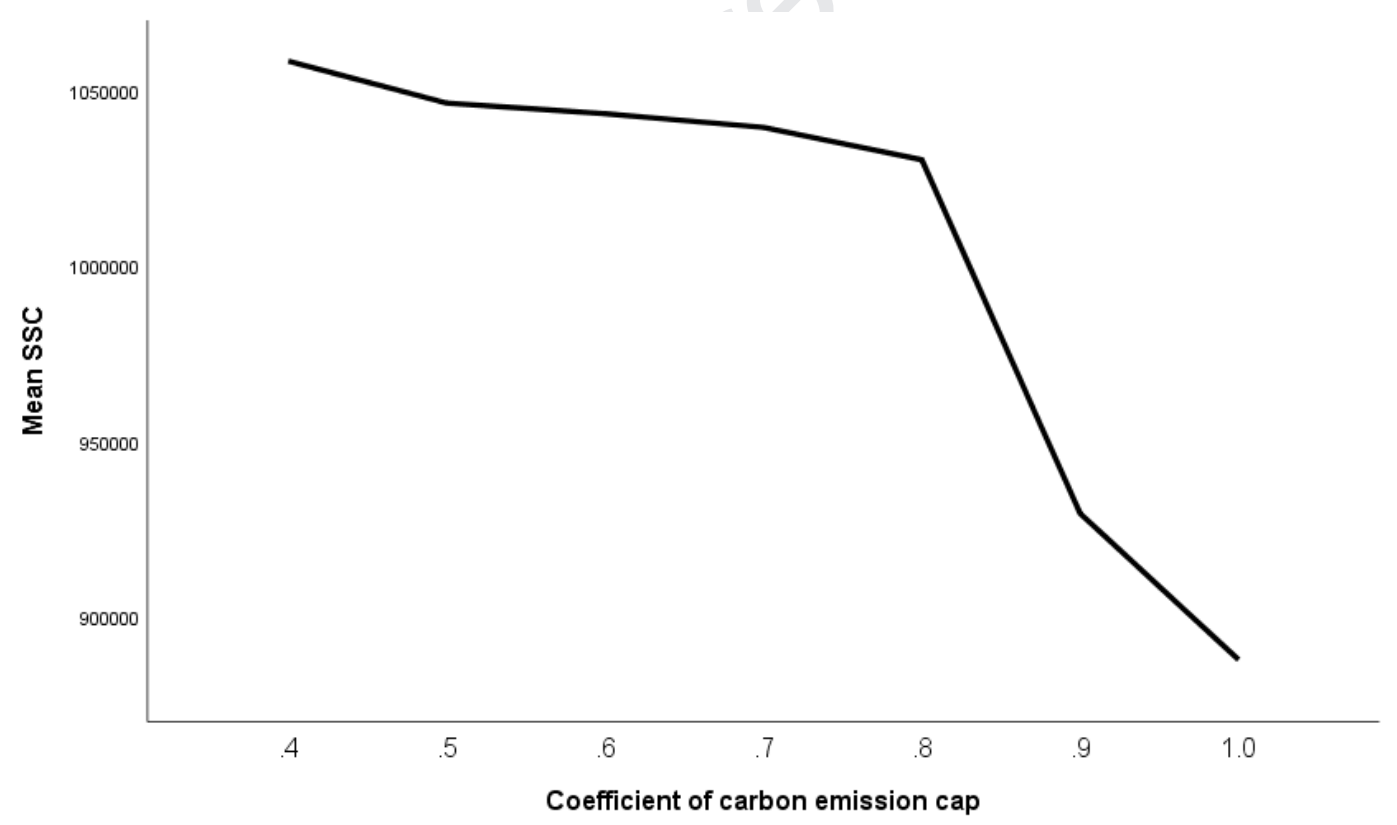

(b) Average safety stock cost.

Fig. 5. Average safety stock level and cost with varying carbon emission caps. 


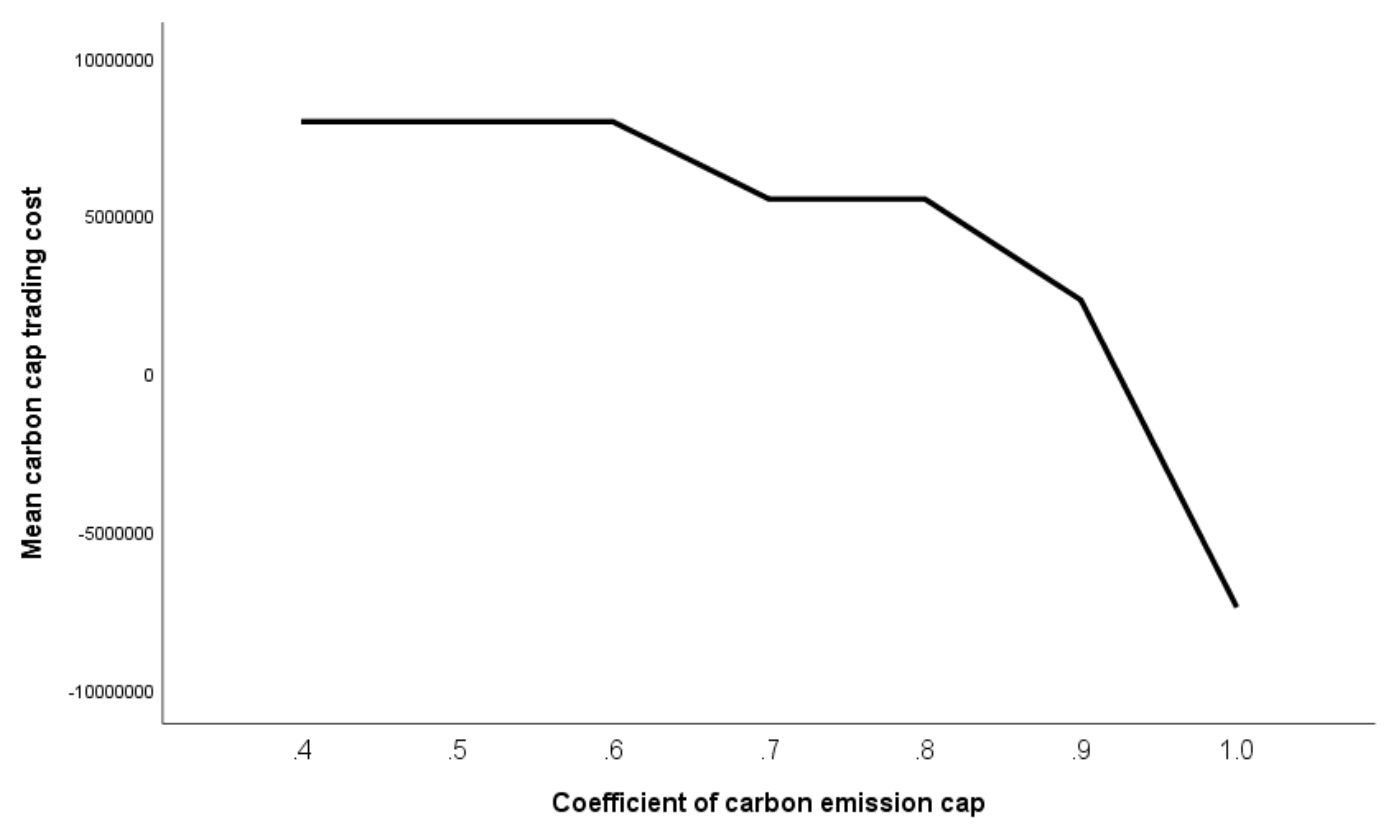

Fig. 6. Average carbon trade cost with varying carbon emission caps.

\subsubsection{Effects of Carbon Trading Price}

The effect of carbon trade price on the average level of safety stock appears to be quite irregular, but a positive relationship in general as shown in Fig. 7(a). This is consistent with the observation from Table 7 that higher carbon cap trading price motivates the firm to quote significantly shorter outbound service times, which increases the average safety stock level. Note that the average SCC in Fig. 7(b) goes down with higher trading price, due to the shift of optimal options to those with less carbon emission and shorter lead time as in Table 7, which offsets the increase of safety stock level.

INSIGHT 3. Higher carbon trading price will tend to increase the level of safety stock, but lead to lower safety stock cost.

Fig. 8 shows that the average carbon emission cost increases with higher trading price at an increasing rate. This is because when a firm has to pay for emission cap, higher trading price will increase the firm's purchase cost of cap. However, the general relationship can be more profound since a firm may be able to have surplus of its emission cap for generating revenue. Therefore, we hypothesize some interactive effect between carbon emission cap and trading price, which will be examined in Section 4.2.4. 


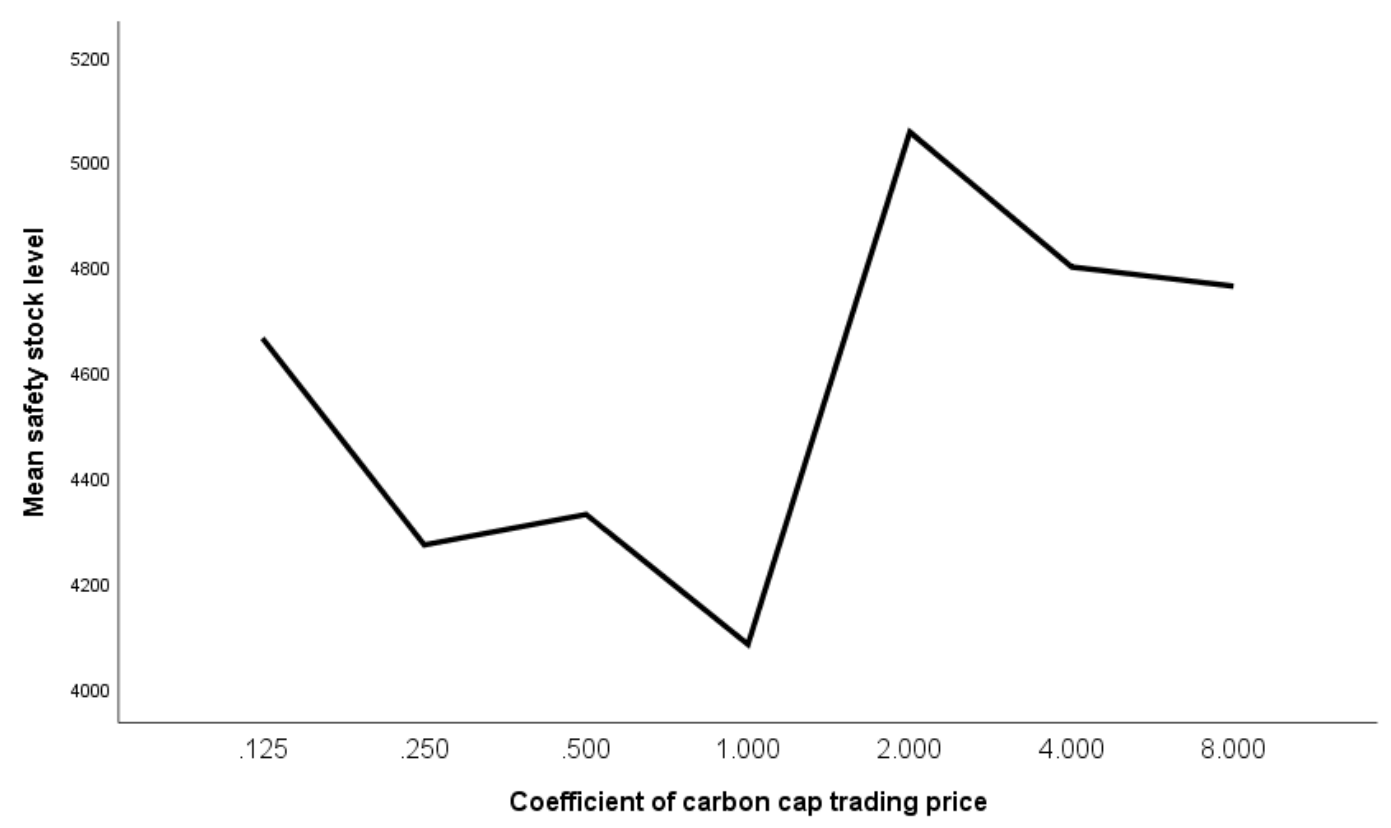

(a) Average safety stock level

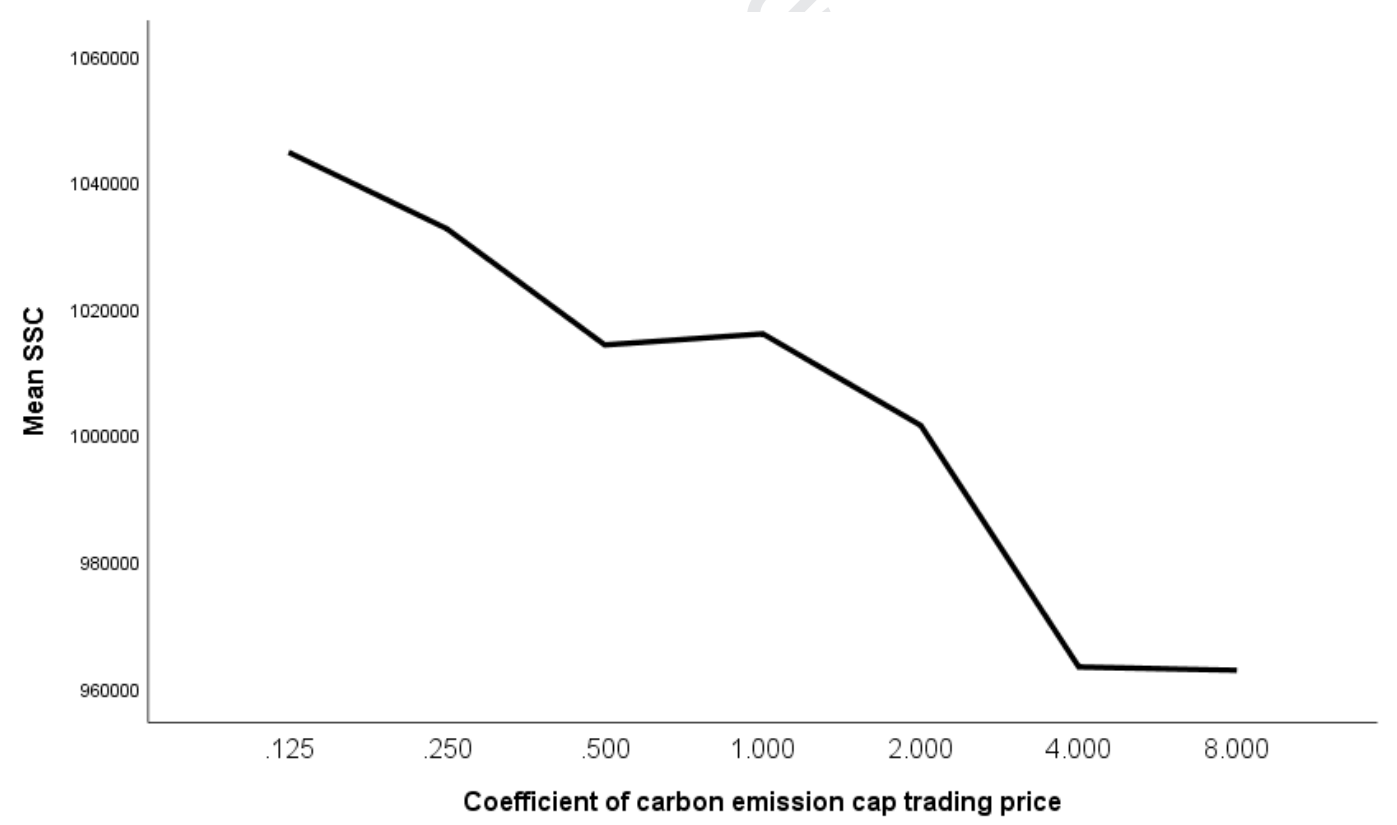

(b)Average safety stock cost

Fig. 7. Average safety stock level and cost with varying carbon cap trading price. 


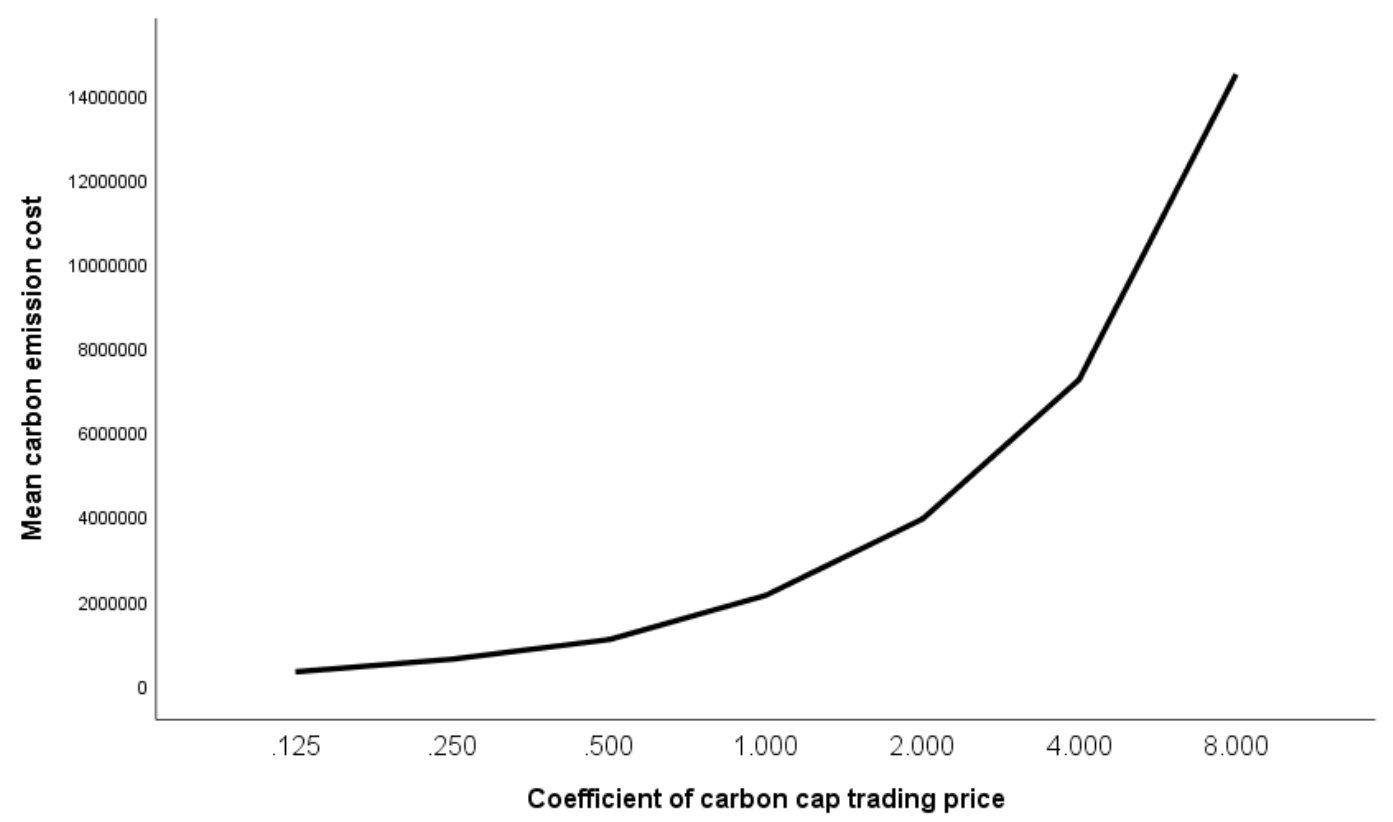

Fig. 8. Average carbon trade cost with varying carbon cap trading cost.

INSIGHT 4. The carbon emission trading cost increases with higher trading price at an increasing rate.

\subsubsection{Effects of Capacity Constraints}

Fig. 9(a) shows that the average safety stock level first decreases when the coefficient of capacity increases from 0.85 to 0.9 , then increases afterwards. Higher operating capacity provides more room for a company to increase its safe ty stock level as needed. The average safety stock cost in Fig. 9(b) decreases with increasing coefficient of capacity, and becomes stable after 0.9. This is due the selection of lower cost options, which offsets the effect of increasing safety stock level.

INSIGHT 5. Higher capacity will tend to increase the safety stock level, but decrease the safety stock cost.

Figure 10 shows that higher operating capacity tends to reduce carbon emission cost, but does not vary when the capacity coefficient is greater than 0.9 . This is because the optimal options shift to those with less carbon emission and shorter lead time initially, and does not vary afterwards. Options with shorter lead time explain why the average safety stock cost is less sensitive with capacity coefficient although the safety stock level increases, as observed in Fig. 9(b). 


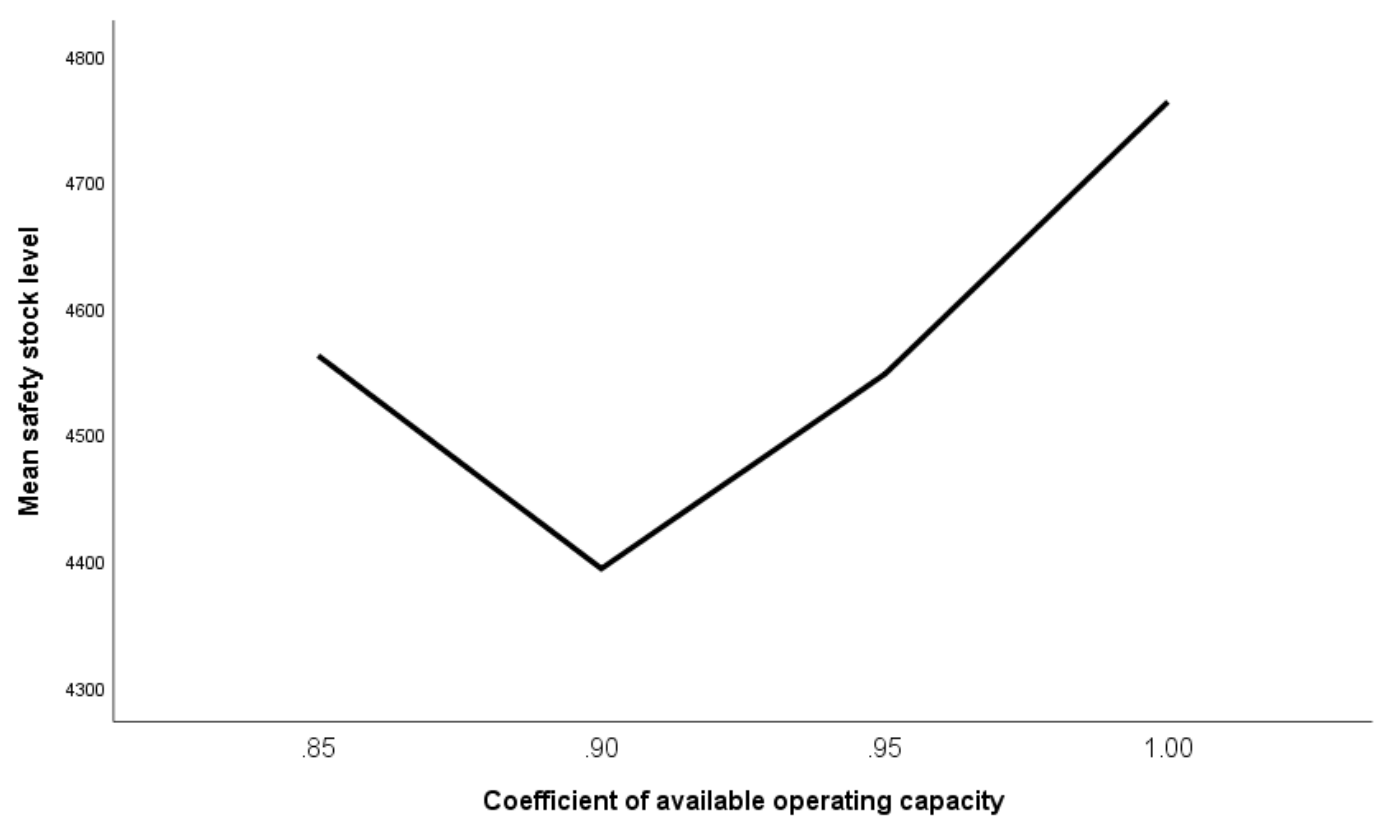

(a) Average safety stock level

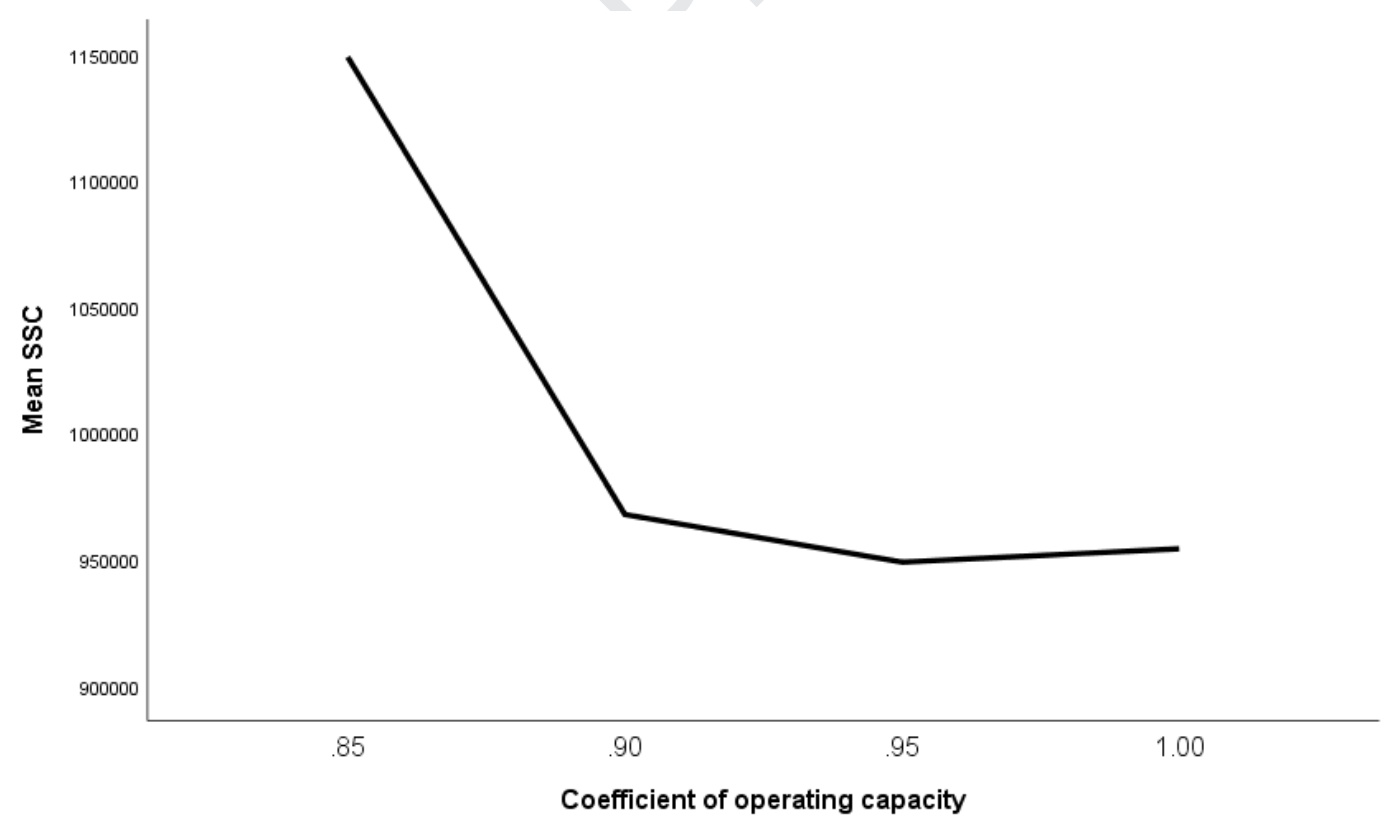

(b) Average safety stock cost

Fig. 9. Average safety stock level and cost with varying ratio of the capacity constraint 


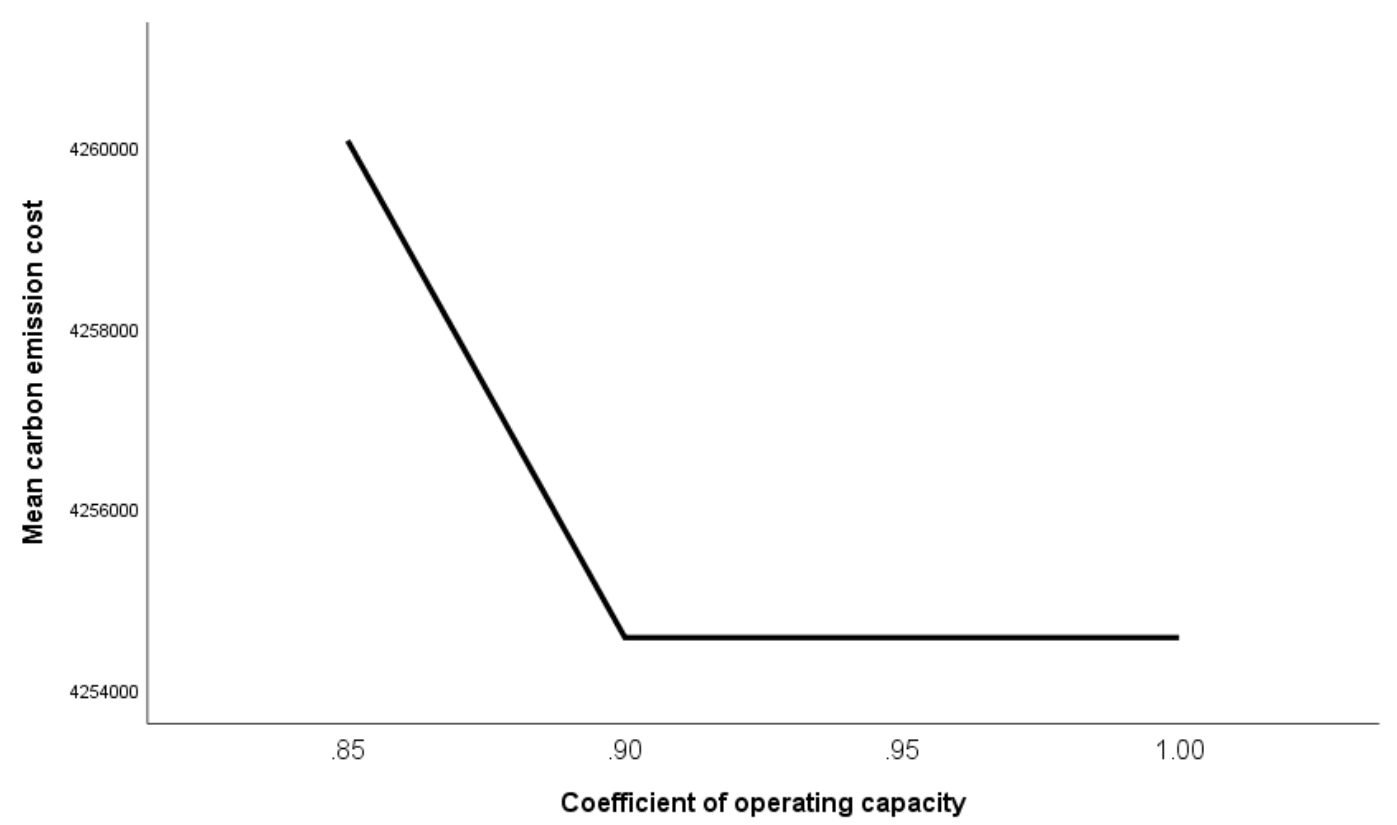

Fig. 10. Average carbon trade cost with varying available operating capacity.

INSIGHT 6. Increasing operating capacity will tend to reduce carbon emission cost, but up to a certain limit.

\subsubsection{Interactive Effects}

We now examine the interactive effects between carbon emission cap and trading price on the optimal SSC and carbon emission cost. Fig. 11 shows that when the carbon emission cap is low, the average optimal SSC does not appear to vary with trading price; when the cap is high, the average optimal SSC tends to increase when trading price decreases.

INSIGHT 7. The effect of carbon trading price on the optimal safety stock cost (SSC) depends on the carbon emission cap. When the cap is high, increasing trading will tend to increase the optimal SSC.

The interactive effect on the optimal carbon emission cost in Fig. 12 shows that when the carbon cap is low, the optimal configuration incurs the amount of emission that exceeds the cap with a cost; when the carbon cap is high, the optimal solution prescribes the amount of emission that is below the cap with a revenue. The effect of carbon cap trading price magnifies either the emission cost or revenue. That is, a firm pays more with higher trading price when the cap is low; it generates more revenue with higher trading price when the cap is high. 
INSIGHT 8. When the carbon trading price is high, the carbon trading cost (or revenue) increases quickly with decreasing (increasing) emission cap.

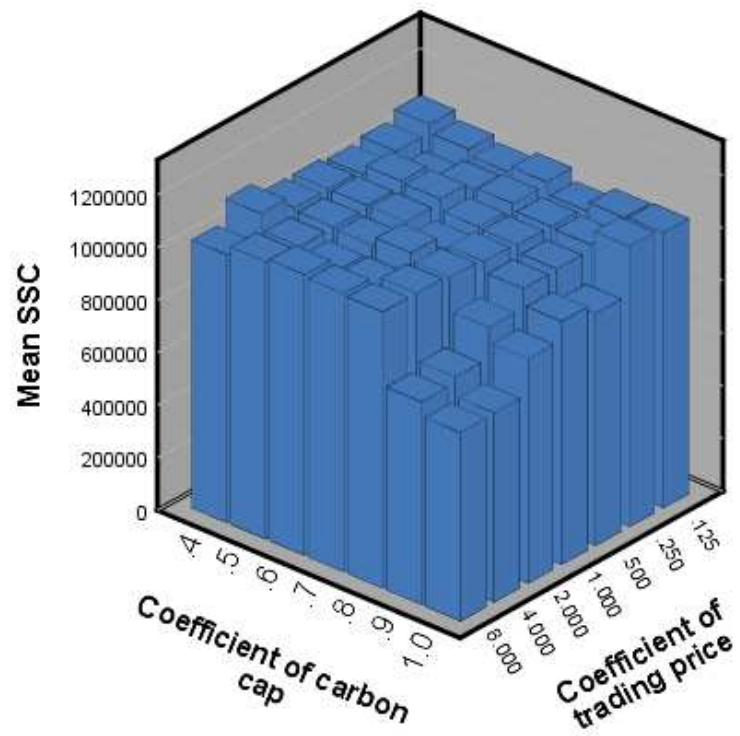

Fig. 11. Average SSC with varying carbon trading price and carbon emission cap.

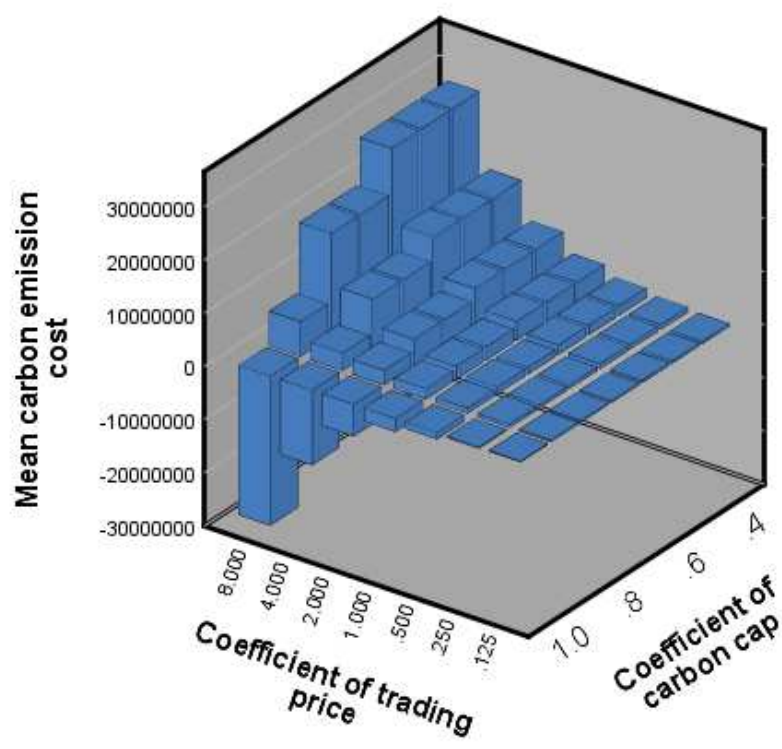

Fig. 12. Average carbon emission cost with varying carbon emission cap and trading price. 


\section{Conclusions and Future Research}

In this paper, we coined the supply chain configuration problem with low carbon emission (SCCP-LCE) to simultaneously optimize cost, lead time and carbon emission for sustainable supply chain operations. A new mixed-integer nonlinear program (MINLP) was developed to model the SCCP-LCE, and a dynamic programming (DP) algorithm was designed to obtain optimal solutions. Comprehensive computational experiments were performed to investigate the impacts of carbon emission constraints, carbon trading price, capacity constraints and demand fluctuation, and their interactive effects on the optimal supply chain configuration and performance.

Our study offers the following main findings and managerial insights. Firstly, it is an effective and feasible means for a firm to expand its operating capacity for carbon emission in order to reduce carbon emission cost in the short-run. When reaching a certain limit, capacity increase will no longer benefit carbon emission cost, which means in the long run, firms would need resort to alternative ways such as environmental-friendly and advanced production for sustainability. Secondly, when a government imposes tight carbon emission cap, a firm will generally incur higher total supply chain costs due to higher safety stock cost and carbon emission cost. The optimal supply chain configuration must best trade-off carbon emission, cost and lead time. In addition, higher carbon trading cost generally results in lower safety stock cost, but its effect on the carbon emission cost depends largely on the carbon cap. This suggests that effective government regulations opt to properly set carbon emission cap and trading price simultaneously.

Coping with carbon emission and improving environmental impact of manufacturing requires concerted efforts between industry and government. Our model and methodologies offer a unified framework for: (i) for manufacturing firms to optimize the configuration of their supply chains with explicit constraints on carbon emission cap and trading opportunity, while achieving the maximum economic and social benefits; and (ii) for government agencies examine the impact of their carbon emission regulatory policies on firms' supply chain operations. With reliable input data and well-designed user-interface, our model and method 
can be deployed for real-world data-driven decision-support in industry. In addition to the value from the business perspective, our study has multi-facet benefits in social and human well-being. Specifically, it prescribes implementable and data-driven solutions for the society to control carbon emission, while achieving the best possible business profitability. Effective and sustainable reduction of carbon emission through this means will, in the long run, help create a healthy ecosystem that benefits the human well-being.

Our work has opened an avenue of future research opportunities. The current model assumes single sourcing, but in practice, multi-sourcing is often implemented when a firm's internal capacity is limited or when there is incentive to mitigate the risk of supply disruption. Thus from the modelling perspective, it will be interesting to extend the model for dealing with multi-sourcing decisions. Our model is also limited with the assumption of deterministic lead times, which can be extended to explicitly consider the variation of lead times ubiquitous in production and transportation. From the computational perspective, the DP algorithm implemented in this paper is limited in its capability for solving large-scale instances. It will be a fruitful direction to develop efficient and effective algorithms for industry strength applications with reasonably large size.

\section{Acknowledgements}

This work was supported by the Guangdong Natural Science Foundation (2017A030313401), China Scholarship Council (201807630004), the Natural Science Foundation of China (51875251), Guangdong Special Support Talent Program - Innovation and Entrepreneurship Leading Team (2019BT02S593), 2018 Guangzhou Leading Innovation Team Program (China)(201909010006), Blue Fire Project (Huizhou) Industry-University-Research Joint Innovation Fund of the Ministry of Education (China) (CXZJHZ201722), and the Fundamental Research Funds for the Central Universities (11618401). We also thank three anonymous referees for their constructive comments that helped improve the contents and exposition of this paper. 


\section{References}

Adams, S., \& Acheampong, A. O. (2019). Reducing carbon emissions: The role of renewable energy and democracy. Journal of Cleaner Production, 240, 118245.

Afrouzy, Z., S. H. Nasseri, I. Mahdavi, and M. M. Paydar. (2016). A Fuzzy Stochastic Multi-objective Optimization Model to Configure a Supply Chain Considering New Product Development. Applied Mathematical Modelling, 40 (17): 7545-7570.

Aggarwal, R. (2018). A chance constraint based low carbon footprint supply chain configuration for an FMCG product. Management of Environmental Quality: An International Journal, 29 (6): 1002-1025.

Amin, S. H., and G. Zhang. (2013). A Three-stage Model for Closed-loop Supply Chain Configuration Under Uncertainty. International Journal of Production Research, 51 (5): $1405-1425$.

Amini M, Li H. (2011).Supply chain configuration for diffusion of new products: An integrated optimization approach. Omega, 39(2011):313-322.

Amini M, Li H. (2015). The impact of dual-market on supply chain configuration for new products. International Journal of Production Research, 53(18): 5669-5684.

Awan, U., Kraslawski, A., \& Huiskonen, J. (2017). Understanding the relationship between stakeholder pressure and sustainability performance in manufacturing firms in Pakistan. Procedia Manufacturing, 11, 768-777.

Baud-Lavigne, B., B. Agard, and B. Penz. (2014). Environmental Constraints in Joint Product and Supply Chain Design Optimization. Computers \& Industrial Engineering, 76: 16-22.

Bellman, R. (1954). The theory of dynamic programming. Bulletin of the American Mathematical Society, 60(6), 503-515.

Benjaafar, S.,Y. Li, and M. Daskin. (2013).Carbon Footprint and the Management of Supply Chains: Insights from Simple Models. IEEE Transactions on Automation Science and Engineering, 10 (1): 99-116.

Brandenburg M. (2015). Low carbon supply chain configuration for a new product-a goal programming approach. International Journal of Production Research, 53(21): 6588-6610.

Böttcher, C. F., \& Müller, M. (2015). Drivers, practices and outcomes of low - carbon operations: approaches of German automotive suppliers to cutting carbon emissions. Business Strategy and the Environment, 24(6), 477-498. 
Cao, K., Xu, X., Wu, Q., \& Zhang, Q. (2017). Optimal production and carbon emission reduction level under cap-and-trade and low carbon subsidy policies. Journal of Cleaner Production, 167, 505-513.

Carter, C. R., \& Rogers, D. S. (2008). A framework of sustainable supply chain management: moving toward new theory. International Journal of Physical Distribution \& Logistics Management, 38(5), 360-387.

Chaabane, A., Ramudhin, A., \& Paquet, M. (2012). Design of sustainable supply chains under the emission trading scheme. International Journal of Production Economics, 135, $37-49$.

Chang, X., Y. Li, Y. Zhao, W. Liu, and J. Wu. (2017). Effects of Carbon Permits Allocation Methods on Remanufacturing Production Decisions. Journal of Cleaner Production, 152: 281-294.

Chelly, A., Nouira, I., Frein, Y., \& Hadj-Alouane, A. B. (2019). On The consideration of carbon emissions in modelling-based supply chain literature: the state of the art, relevant features and research gaps. International Journal of Production Research, 57(15-16), 4977-5004.

Chen, H. and Li, P. (2015). Optimization of (r, q) policies for serial inventory systems using the guaranteed service approach. Computers \& Industrial Engineering, 80(0):261-273.

Correia, F., Howard, M., Hawkins, B., Pye, A., \& Lamming, R. (2013). Low carbon procurement: An emerging agenda. Journal of Purchasing and Supply Management, 19(1), $58-64$.

Das, C., \& Jharkharia, S. (2018). Low carbon supply chain: A state-of-the-art literature review. Journal of Manufacturing Technology Management, 29(2), 398-428.

De, A., Pratap, S., Kumar, A., \& Tiwari, M. K. (2018). A hybrid dynamic berth allocation planning problem with fuel costs considerations for container terminal port using chemical reaction optimization approach. Annals of Operations Research, 1-29.

De, A., Wang, J., \& Tiwari, M. K. (2019). Fuel Bunker Management Strategies Within Sustainable Container Shipping Operation Considering Disruption and Recovery Policies. IEEE Transactions on Engineering Management, 1-23.

De, A., Wang, J., \& Tiwari, M. K. (2020). Hybridizing Basic Variable Neighborhood Search With Particle Swarm Optimization for Solving Sustainable Ship Routing and Bunker Management Problem. IEEE Transactions on Intelligent Transportation Systems, 21(3), 986-997. 
Diabat A, AbdallahT,Al-RefaieA,SvetinovicD,GovindanK. (2013). Strategicclosed-loop facility location problem with carbon market trading. IEEE Transactionson Engineering Management, 60(2):398-408.

Dinan, T., (2008). Year. Policy Options for Reducing CO2 Emissions. Congress of the US. Congressional Budget Office.

Eruguz, A. S., Sahin, E., Jemai, Z., \& Dallery, Y. (2016). A comprehensive survey of guaranteed-service models for multi-echelon inventory optimization. International Journal of Production Economics, 172, 110-125.

Eskandarpour, M., Dejax, P., Miemczyk, J., Peton, O., (2015). Sustainable supply chain network design: an optimization-oriented review. Omega, 54, 11-32.

Fahimnia, B., Sarkis, J., Boland, J., Reisi, M., \& Goh, M. (2015). Policy insights from a green supply chain optimisation model. International Journal of Production Research, 53(21), 6522-6533.

Graves, S. C. and Schoenmeyr, T. (2016). Strategic safety-stock placement in supply chains with capacity constraints. Manufacturing \& Service Operations Management, 18 (3):445-460.

Graves, S. C.; Willems, S. P., (2000). Optimizing strategic safety stock placement in supply chains. Manufacturing \&Service Operations Management, 2, (1), 68.

Graves S C, Willems S P. (2001).Optimizing the supply chain configuration for new products. Working paper. Leaders for Management Program and A.P., Sloan School of Management, MIT.

Graves, S. C.; Willems, S. P., (2005). Optimizing the supply chain configuration for new products. Management Science, 51, (8), 1165.

Hong, Z., Dai, W., Luh, H., \& Yang, C. (2018). Optimal configuration of a green product supply chain with guaranteed service time and emission constraints. European Journal of Operational Research, 266(2), 663-677.

Hua, N. G., \& Willems, S. P. (2016). Optimally configuring a two-stage serial line supply chain under the guaranteed service model. International Journal of Production Economics, 181, 98-106.

Huang G Q, Zhang X Y, Liang L. (2005). Towards integrated optimal configuration of platform products, manufacturing processes, and supply chains. Journal of Production Economics, 23(2-4):267-290. 
Huang, P., Zhang, X., \& Deng, X. (2006). Survey and analysis of public environmental awareness and performance in Ningbo, China: a case study on household electrical and electronic equipment. Journal of Cleaner Production, 14(18), 1635-1643.

Humair, S., \& Willems, S. P. (2006). Optimizing strategic safety stock placement in supply chains with clusters of commonality. Operations Research, 54(4), 725-742.

Inderfurth, K., (1991). Safety Stock Optimization in Multi-Stage Inventory Systems. International Journal of Production Economics, 24, 103.

Inderfurth, K.; Minner, S., (1998).Safety stocks in multi-stage inventory systems under different service measures. European Journal of Operations Research, 106, 57.

Klosterhalfen, S. T., Minner, S., and Willems, S. P. (2014). Strategic safety stock placement in supply networks with static dual supply. Manufacturing \& Service Operations Management, 16(2):204-219.

Kumar, K. and Aouam, T. (2018). Integrated lot sizing and safety stock placement in a network of production facilities. International Journal of Production Economics, 195:7495.

Kuo, T. C., Tseng, M. L., Chen, H. M., Chen, P. S., \& Chang, P. C. (2018). Design and analysis of supply chain networks with low carbon emissions. Computational Economics, 52(4), 1353-1374.

Li, H., Amini M. (2012). A hybrid optimisation approach to configure a supply chain for new product diffusion: a case study of multiple-sourcing strategy. International Journal of Production Research, 50(11): 3152-3171.

Li, H. and Jiang, D. (2012). New model and heuristics for safety stock placement in general acyclic supply chain networks, Computers \& Operations Research, 39: 1333-1344.

Li, H., Womer, K.,(2008). Modeling the supply chain configuration problem with resource constraints, International Journal of Project Management, 26(6): 646-654.

Li, H., Womer, K. (2012). Optimizing the supply chain configuration for make-to-order manufacturing, European Journal of Operational Research, 221(1): 118-128.

Li, P., Chen, H., and Che, A. (2013). Optimal batch ordering policies for assembly systems with guaranteed service. International Journal of Production Research, 51(20):6275-6293.

Magnanti, T.L., Shen, Z.-J., Shu, J., Simchi-Levi, D, Teo, C.-P. (2006). Inventory placement in acyclic supply chain networks. Operations Research Letters, 34:228-38.

Mao, Z., Zhang, S., \& Li, X. (2017). Low carbon supply chain firm integration and firm performance in China. Journal of Cleaner Production, 153, 354-361. 
Negahban, A., \& Dehghanimohammadabadi, M. (2018). Optimizing the supply chain configuration and production-sales policies for new products over multiple planning horizons. International Journal of Production Economics, 196, 150-162.

Ni, W., \& Shu, J. (2015). Trade-off between service time and carbon emissions for safety stock placement in multi-echelon supply chains. International journal of production research, 53(22), 6701-6718.

Nie, D., Qu, T., Liu, Y., Li, C., \& Huang, G. Q. (2019). Improved augmented Lagrangian coordination for optimizing supply chain configuration with multiple sharing elements in industrial cluster. Industrial Management \& Data Systems, 119(4), 743-773.

Qu, T. Huang, G.Q., Cung, Van-Dat, Mangione, Fabien, (2010). Optimal Configuration of Assembly Supply Chains Using Analytical Target Cascading. International Journal of Production Research, 48(23), 6883 - 6907.

Qu, T., D. X. Nie, X. Chen, X. D. Chen, Q. Y. Dai, and G. Q. Huang. (2015). Optimal Configuration of Cluster Supply Chains with Augmented Lagrange Coordination. Computers \& Industrial Engineering, 84: 43-55.

Qu, T., Nie, D. X., Li. C.D. et al. (2017). Optimal configuration of assembly supply chains based on Hybrid augmented Lagrangian coordination in an industrial cluster. Computers \&Industrial Engineering, 112,511-525.

Ramudhin, A., Chaabane, A., \& Paquet, M. (2010). Carbon market sensitive sustainable supply chain network design. International Journal of Management Science and Engineering Management, 5(1), 30-38.

Rahmani, D., \& Mahoodian, V. (2017). Strategic and operational supply chain network design to reduce carbon emission considering reliability and robustness. Journal of Cleaner Production, 149, 607-620.

Sahebjamnia, N., Fathollahi-Fard, A. M., \& Hajiaghaei-Keshteli, M. (2018). Sustainable tire closed-loop supply chain network design: Hybrid metaheuristic algorithms for large-scale networks. Journal of cleaner production, 196, 273-296.

Schoenmeyr, T., \& Graves, S. C. (2009). Strategic safety stocks in supply chains with evolving forecasts. Manufacturing \& Service Operations Management, 11(4), 657-673.

Shaharudin, M. S., Fernando, Y., Jabbour, C. J. C., Sroufe, R., \& Jasmi, M. F. A. (2019). Past, present, and future low carbon supply chain management: A content review using social network analysis. Journal of Cleaner Production, 218, 629-643. 
Shaw, K., Irfan, M., Shankar, R., \& Yadav, S. S. (2016). Low carbon chance constrained supply chain network design problem: a Benders decomposition based approach. Computers \& Industrial Engineering, 98, 483-497.

Sherafati, M., Bashiri, M., Tavakkoli-Moghaddam, R., \& Pishvaee, M. S. (2019). Supply chain network design considering sustainable development paradigm: A case study in cable industry. Journal of Cleaner Production, 234, 366-380.

Silver, E.A.,Pyke,D.F., Peterson,R.,(1998).Inventory Management and Production Planning and Scheduling.

Simpson, K. F., (1958).In-process inventories. Operations Research, 6, 863.

Sitompul, C., Aghezzaf, E.-H., Dullaert, W., and Landeghem, H. V.,(2008). Safety stock placement problem in capacitated supply chains. International Journal of Production Research, 46(17):4709-4727.

Waltho, C., Elhedhli, S., \& Gzara, F. (2019). Green supply chain network design: A review focused on policy adoption and emission quantification. International Journal of Production Economics, 208,305-318.

Wang, F. , Lai, X. , \& Shi, N. (2011). A multi-objective optimization for green supply chain network design. Decision Support Systems, 51 (2), 262-269.

Yang, J., Tang, L., Mi, Z., Liu, S., Li, L., \& Zheng, J. (2019). Carbon emissions performance in logistics at the city level. Journal of Cleaner Production, 231, 1258-1266.

Yao, X., \& Askin, R. (2019). Review of supply chain configuration and design decision-making for new product. International Journal of Production Research, 57(7), 2226-2246.

You, F. \& Grossmann, I. E. (2010). Integrated multi-echelon supply chain design with inventories under uncertainty: MINLP models, computational strategies. American Institute of Chemical Engineers Journal, 56(2):419-440.

You, F. and Grossmann, I. E. (2011). Balancing responsiveness and economics in process supply chain design with multi-echelon stochastic inventory. American Institute of Chemical Engineers Journal, 57(1):178-192. 


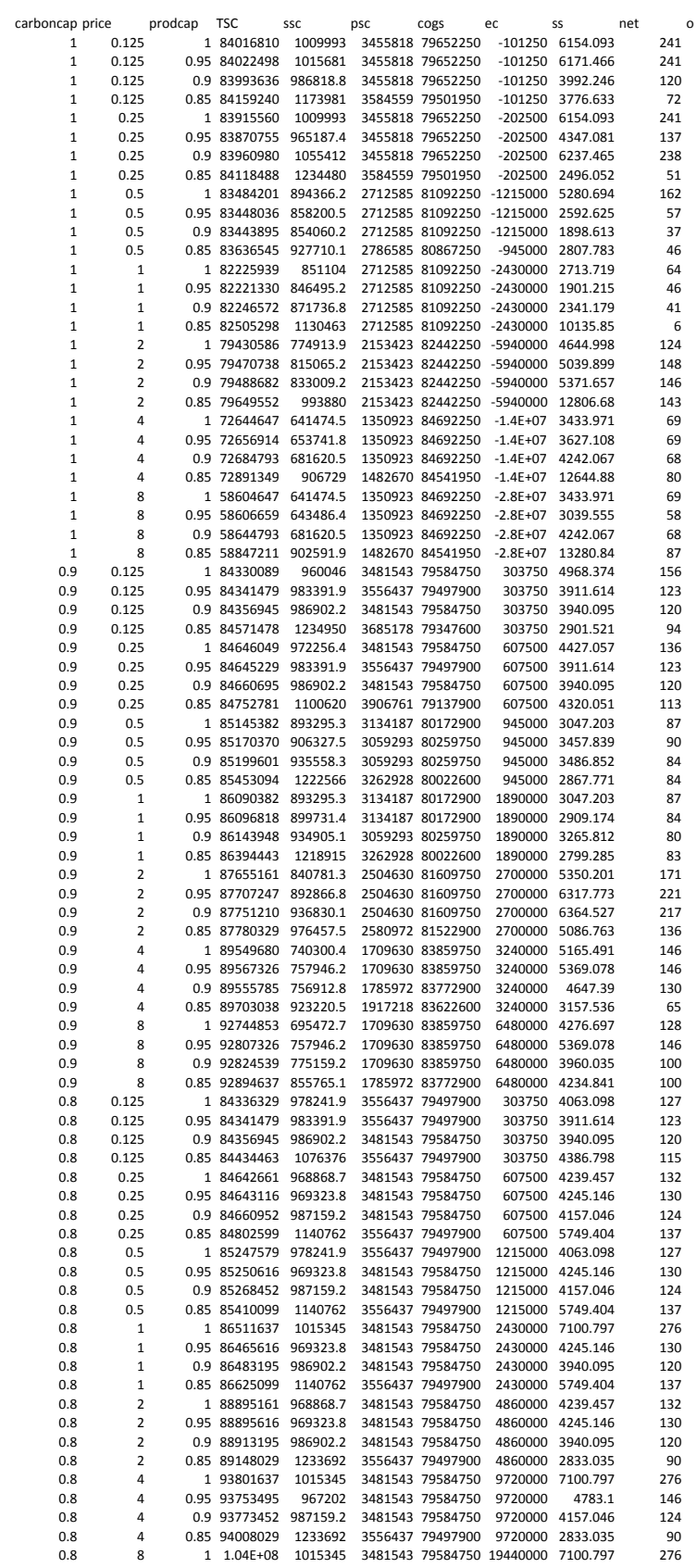




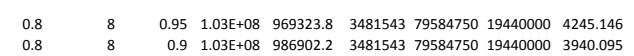

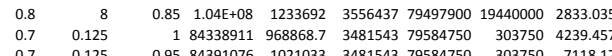

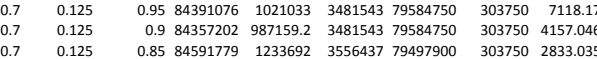

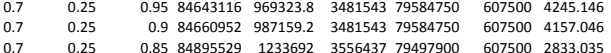

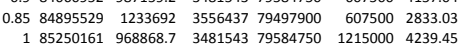

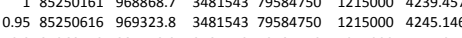

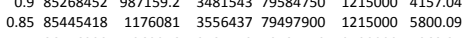

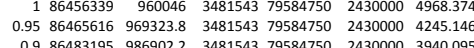

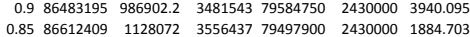

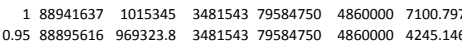

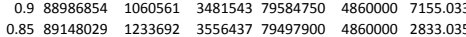
$\begin{array}{llllll}193756226 & 969933.8 & 3481543 & 79584750 & 9720000 & 4679.087\end{array}$

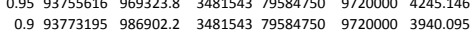
$\begin{array}{lllllll}0.85 & 93915099 & 1140762 & 3556437 & 79497900 & 9720000 & 5749.404\end{array}$

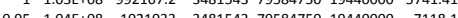
$0.91 .03 E+08987159.2348154379584750194440000 \quad 4157.046$

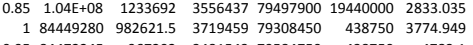
$348154379584750 \quad 438750 \quad 4783$.

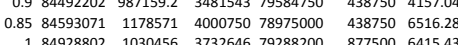

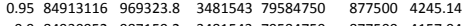

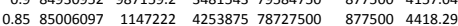
$\begin{array}{lllll}185773194 & 1025319 & 3905375 & 79087500 & 1755000 \\ 0016.139\end{array}$

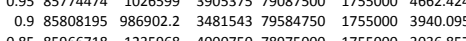
$\begin{array}{lllllll}1 & 87524408 & 1021533 & 3905375 & 79087500 & 35500000 & 40363.28\end{array}$ $0.9875631955986902 .2348154379584750 \quad 3510000 \quad 3940.055$

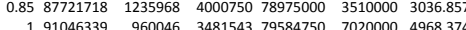
$\begin{array}{llllllll}0.95 & 91107326 & 1021033 & 3481543 & 79584750 & 7020000 & 7118.17\end{array}$

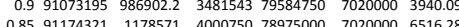
$\begin{array}{lllll}1 & 98075161968868.7348154379584750 & 14040000 & 4239.45\end{array}$ 0.9598075616969323 .8348815437958877501404000004245 .14

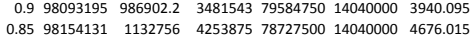

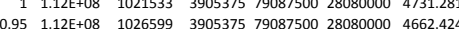

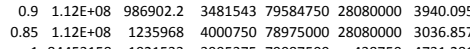

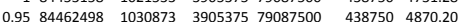
$0.984522083 \quad 1017041348154379584750 \quad 43875041999.91$

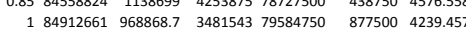
$0.9584913116969323 .83481543795584750 \quad 877500 \quad 4245.14$

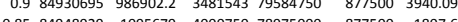

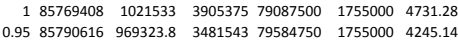
$\begin{array}{lllllll}0.85 & 85909321 & 1178571 & 4000750 & 78975000 & 1755000 & 6516289\end{array}$ $\begin{array}{llllllll}1 . & 87524408 & 1021533 & 3905375 & 79087500 & 3510000 & 4731.28\end{array}$

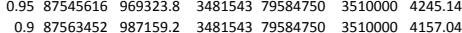

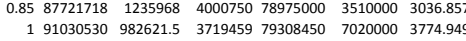

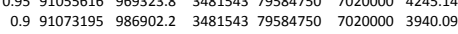

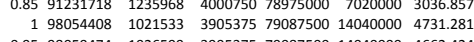

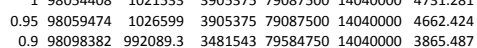




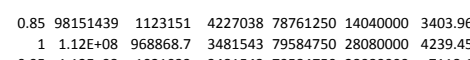

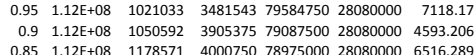

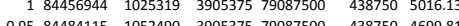

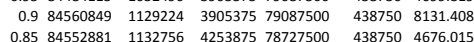

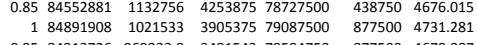

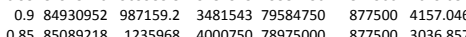
$185765530982621.53771945979308450 \quad 17550003774949$

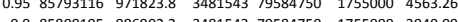

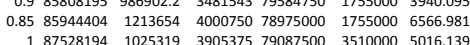

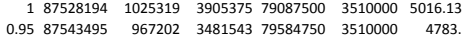
$\begin{array}{lllllll}0.9987563452 & 987159.2 & 3481543 & 79584750 & 3510000 & 4157.046\end{array}$

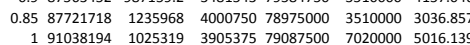

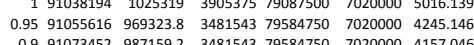

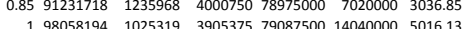
$0.9598059474 \quad 1026599390537579087500140440000 \quad 4662.42$

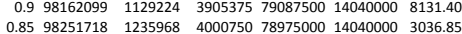
$\begin{array}{lllll}1 & 1.12 E+08 & 1021533 & 3905375 & 79087500 \\ 0 & 280800000 & 47312\end{array}$

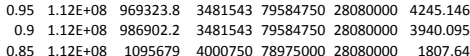

84
84
132
276
146
197
161
151
316
134
155
142
124
97
121
138
120
197
161
146
124
97
161
130
124
97
161
151
316
97
155
130
120
56
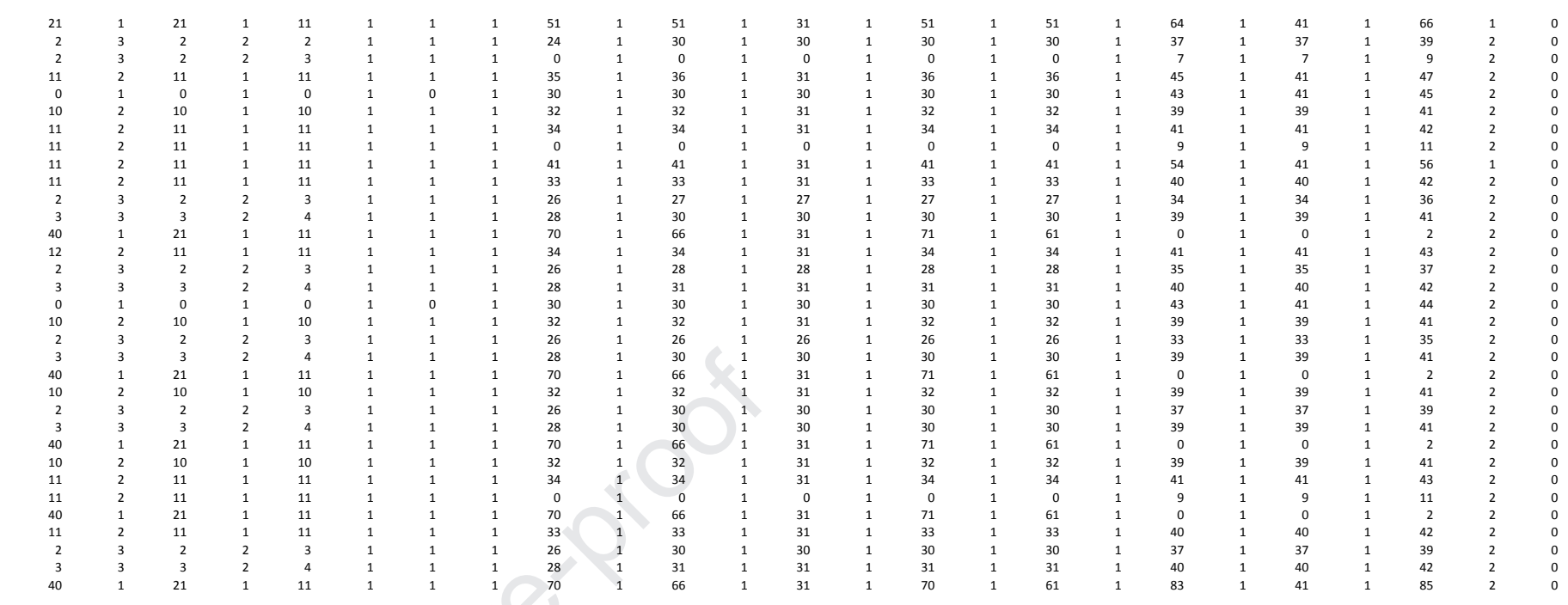


\section{Declaration of interests}

$\bigotimes$ The authors declare that they have no known competing financial interests or personal relationships that could have appeared to influence the work reported in this paper.

$\square$ The authors declare the following financial interests/personal relationships which may be considered as potential competing interests:

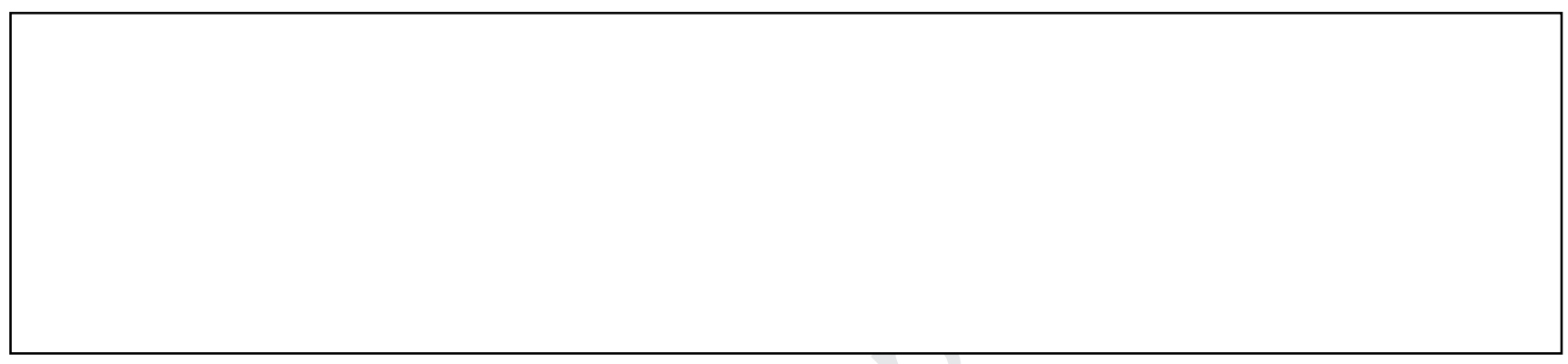

